\title{
FERRITIN IRON UPTAKE AND RELEASE IN THE PRESENCE OF METALS AND METALLOPROTEINS: CHEMICAL IMPLICATIONS IN THE BRAIN
}

Fernando Carmona ${ }^{a}$, Òscar Palacios ${ }^{b}$, Natividad Gálveza, Rafael Cuestac, Sílvia Atrian $^{\mathrm{d}}$, Mercè Capdevilab ${ }^{\mathrm{b}}$ José M. Domínguez-Vera ${ }^{\mathrm{a}}$.

a Departamento de Química Inorgánica and Instituto de Biotecnología, Facultad de Ciencias, Universidad de Granada, E-18071 Granada, Spain

b Departament de Química, Facultat de Ciències, Universitat Autònoma de Barcelona, Cerdanyola del Vallès, E-08193 Barcelona, Spain

c Departamento de Química, Escuela de Linares, Universidad de Jaén, Jaen, Spain

d Departament de Genètica, Facultat de Biologia and Institut de Biomedicina, Universitat de Barcelona, Avda. Diagonal 643, E-08028 Barcelona, Spain

\section{Abstract}

Living organisms have developed a chemical machinery based on the ferritin protein for the storage, under a nontoxic form, of the iron that is not required for immediate metabolic purposes. Whereas free iron causes extensive cell damage, ferritin iron is not toxic, yet still available for cell requirements. However, iron storage in ferritin is increasingly being recognized as a crucial process related with some neurodegenerative disorders and therefore, an understanding of the management of iron in the brain, especially the processes of iron uptake and release in ferritin, is compulsory to clarify the role of this metalloprotein in these neuropathologies.

Although knowledge of iron storage and iron release in ferritin is nowadays still limited, even less information is currently available about the influence of free metal ions and other brain metalloproteins in these processes.

In this sense, this review is an excellent opportunity to collect all the information today available about the influence of metals and metalloproteins in ferritin loading and unloading events, which until now are dispersed in the literature. Furthermore, we will focus on the importance of all the above-mentioned interactions in the brain, since the importance of the correct and safe balance of metals in the brain after their well-known implication in neurodegenerative 
processes such as the Alzheimer's (AD), Parkinson (PD) and prion protein (PPD) diseases is obvious. In this work, we will not only recall the importance and role of ferritin in the brain but also the putative influence of the interaction between ferritin and some metals and/or metalloproteins and other biomolecules on these neurological dysfunctions. The final part of the review will be devoted to draw some guidelines to where the future prospects point to on the basis of the existing information.

\section{Introduction}

Iron is essential for life since it is required for the active sites of many metalloproteins that play a key role in crucial biological processes such as oxygen transport, storage and use of oxygen in many oxidation-reduction reactions as well as in electron transfer reactions within the cell [1]. Particularly in the brain, iron is crucial for neuronal development, gene expression, enzyme function, dopamine, heme and iron-sulfur cluster synthesis as well as electron transport [2]. However, excess iron is highly toxic. Iron(II) promotes the formation of highly reactive oxygen species (ROS) via distinct pathways [3]. Among these, the most common one is the Fenton reaction, in which hydroxyl radicals $\mathrm{OH} \bullet$ are produced by the reaction of iron(II) and hydrogen peroxide. ROS are extremely powerful oxidizing agents capable of causing irreversible cell damage, organ failure and eventually death [4]. Furthermore, free iron is a key nutrient for pathogenic microorganisms, which require iron to survive and replicate. Life is, in some way, a battle for iron and therefore, hosts must deprive undesirable guests of iron in order to combat the infections they cause. Therefore, both excess and deficiency of iron are harmful, and organisms have been forced to develop mechanisms to manage this situation. To do so, they store the iron that is not required for immediate metabolic needs in a non-toxic form. This stored iron is neither available for producing damaging radicals nor for allowing the viability of pathogen microorganisms. Once required, iron can be recovered from the store to participate in cell metabolism.

Ferritin is the primary iron storing protein in most living organisms throughout the animal, plant and microbial kingdoms. The structure of many ferritins isolated 
from a wide range of organisms and biological tissues have been determined, and it becomes evident that a common structure has been conserved throughout evolution. The most extensively studied ferritin is that of horse spleen, traditionally considered as the model of mammalian ferritin. It consists of a hollow protein shell ( $\mathrm{Mr}$ about $450 \mathrm{kDa}$ ) composed of 24 subunits arranged in cubic symmetry, that surrounds an aqueous cavity of $8 \mathrm{~nm}$ in diameter, capable 0 accommodating thousands of iron atoms as an iron(III) mineral, traditionally described as ferrihydrite [ $\mathrm{Fe}^{\mathrm{III}}{ }_{10} \mathrm{O}_{14}(\mathrm{OH})_{2}$ ] [5]. Ferrihydrite is consistent with a single hexagonal phase ( $\mathrm{P}_{3} \mathrm{mc}$; $\mathrm{a}=\sim 5.95 \AA$, $\mathrm{c}=\sim 9.06 \AA$ ). In its ideal form, this structure contains $20 \%$ tetrahedrally and $80 \%$ octahedrally coordinated iron(III) [6].

However, it is important to note that the nature of the ferritin core is not completely accepted. In fact, recent studies have pointed out that a polyphasic model, including ferrihydrite and magnetite (or other iron(II)-containing phases) would describe in a more realistic manner the ferritin core, especially once the protein has undergone some chemical disorder [7]. In any case, ferrihydrite is certainly a labile mineral and it is therefore the ideal choice to allow an adequate turn over of iron from the ferritin store to the cell.

Ferritin is remarkably stable to temperature and $\mathrm{pH}$ changes, as demonstrated by its stability up to $70{ }^{\circ} \mathrm{C}$ and over extreme $\mathrm{pH}$ values of $3-10$. At $\mathrm{pH}<3$ the 24 subunits dissociate but reversibly reassemble at $\mathrm{pH}>3$ [8]. The 24-polypeptide chains of the apoferritin shell can be classified into two types: the $\mathrm{H}$ (or heavy) subunits of 178 amino acids and $21 \mathrm{kDa}$, and the L (or light) subunits with 171 amino acids and $19 \mathrm{kDa}$, Fig. 1. The two types of ferritin subunits are closely related both in terms of primary ( $\sim 53 \%$ protein sequence identity) and tertiary structure $[9,10]$. However they have different functionality. Thus, whereas the $\mathrm{H}$ subunit plays a key role in the rapid detoxification of iron, since it contains a catalytic ferroxidase center for rapid iron(II) oxidation, the L subunit is associated with iron nucleation, mineralization and long-term iron storage in the ferritin cavity [11]. In agreement with this, the $\mathrm{H} / \mathrm{L}$ ratio in a ferritin shell varies widely in different tissues. L-subunit-rich ferritins predominate in iron storage organs such as the liver and spleen, while organs that require iron detoxification properties such as the heart and brain contain H-rich ferritins [12] 


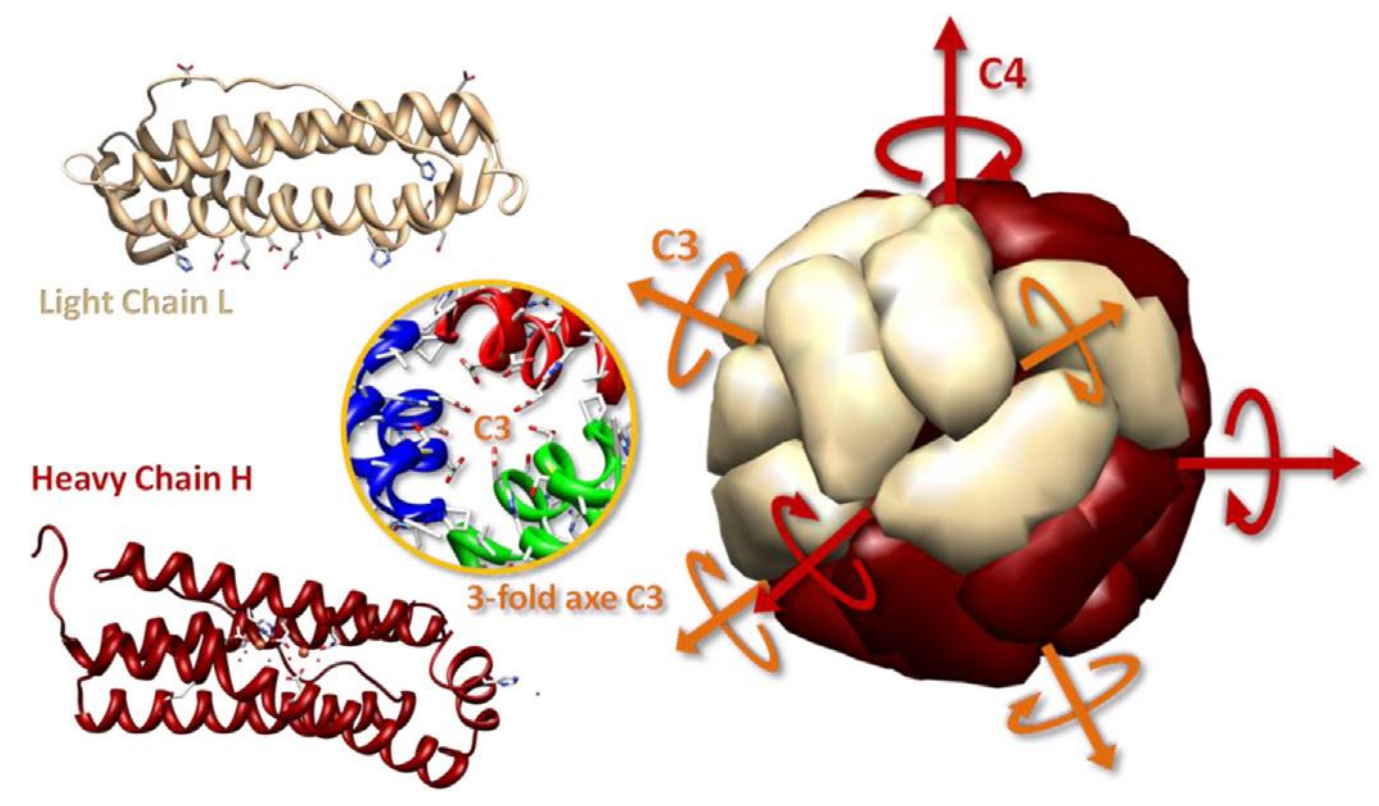

Fig. 1. Horse spleen ferritin structure: a 24-subunit oligomer with a combination of heavy $(H)$ and light (L) polypeptide subunits that form a spherical hollow molecule.

It is interesting to note that ferritins in bacteria, plants and invertebrates are exclusively made by $\mathrm{H}$-like subunits, i.e. they are pure $\mathrm{H}$-like ferritins. Ferritins with a combination of $\mathrm{H}$ and $\mathrm{L}$ subunits are found only in vertebrates, and they have thoroughly been characterized in mammals. As an example, the traditionally considered model of mammalian ferritin, horse spleen ferritin, usually contains $90 \% \mathrm{~L}-$ and $10 \% \mathrm{H}$ - subunits.

The multimeric construction of the ferritin shell allows the generation of different types of channels leading to the polymer cavity. Eight hydrophilic channels of $\sim 4-5$ $\AA$ in diameter and with C3 symmetry (Fig. 1) allow the transfer of water, metal cations and hydrophilic molecules of the appropriate size from the external solution to the cavity or vice versa.

Synthesis of the ferritin $\mathrm{H}$ and $\mathrm{L}$ monomers is mainly regulated at translation level in response to labile iron concentrations by two mRNA-binding proteins: IRP1 and IRP2 (iron-regulator protein). When cytoplasmic iron is high, IRP1 forms a Fe-S protein that acts as the aconitase enzyme. When iron is low, IRP1 adopts an open 
conformation, devoid of the Fe-S cluster that binds to the $5^{\prime}$ iron responsive elements (IRE) of the ferritin mRNA, this repressing its translation [13]. Conversely, IRP2 presence in the cell is regulated by degradation, quickly induced by iron overload [14]. These systems function in close coordination with an antithesis control of the transferrin receptor (TfR) synthesis, because the union of IRP1 to the 3' loops of TfR mRNA in low iron conditions stabilizes this messenger, increasing the synthesis rate of $\mathrm{TfR}$, and therefore provoking an enhanced transferrin uptake. However, besides this smart control mechanism exerted by iron levels, at least ferritin $\mathrm{H}$ synthesis is also transcriptionally regulated by classical promoter elements and transcription factors that act in inflammatory scenarios [15], which would account for the H-rich ferritin shells usually associated with this kind of processes.

Disorders in ferritin functions have been related with typical iron-related diseases, such as hemochromatosis or anemia, but ferritin is also increasingly being recognized as a crucial molecule in some neurological pathologies, as Parkinson (PD) or Alzheimer's (AD) diseases [16]. Therefore, knowing the ferritin iron uptake, storage, and release mechanisms in detail becomes a challenge for the scientific community in order to understand the etiology of these syndromes and eventually to approach the design of new therapeutic agents based on iron metabolism.

The ferritin core forms from iron(II), and not iron(III). As it will be discussed in the next sections, iron(II) is oxidized and stored mainly as an iron(III) mineral. Likewise, when the cell requires iron from ferritin this is removed as iron(II). If the ferritin protein is purely viewed as an iron store, there are two processes that have to operate properly: a fast and efficient iron storage, and a controlled release of iron. In a biological scenario, when ferritin loses its iron storing ability, free iron(II) remains in the cytoplasm. Equally, when ferritin releases iron in an uncontrolled manner, iron(II) is produced and dumped into the cytoplasm. In other words, a dysfunction of ferritin always gives rise to the existence of free iron(II), with independence of the reason of its malfunction. As mentioned above, free iron(II) promotes ROS that produces oxidative damage. Interestingly, oxidative damage in neurons is a primary cause of degenerative diseases such as AD [17]. Furthermore, as recently reviewed by Kozlowski et al. [18], Fernández et 
al. [19], Hureau and Dorlet [20] and Viles [21], free iron(II) and other metals might contribute to some neurological diseases by inducing aggregation of some proteins, as it is the case of $\beta$-amyloid, $\alpha$-synuclein or the prion protein that respectively accumulate in patients of $\mathrm{AD}, \mathrm{PD}$ and prion protein disease (PPD).

The reasons for the malfunctioning of ferritin, either at iron uptake, storage or iron release, are still not clear, but data are increasingly supporting two lines of evidence. First, the existence of an excess of a chemical reductant interacting with ferritin has been postulated [22]. Second, genetic mutations affecting either the structure of the ferritin polypeptide [23], or the H [24] or L [25] ferritin mRNA IRE regions this leading to undesirable $\mathrm{H} / \mathrm{L}$ ratios in the ferritin shells have been recently reported. Both mentioned pathways of ferritin dysfunctions have been intensively studied, related to neurological disorders and reviewed [26].

Ferritin can bind or accommodate metal ions other than Fe in several types of binding sites $[27,28]$. More importantly, the disruption of the ferritin function in iron uptake or iron release is influenced by the presence of some metals [29], some metalloproteins [30,31], and some other types of biomolecule. Zinc(II), for example, binds to specific ferritin sites and inhibits ferritin iron core formation [32-39]. Copper(II) also binds tightly to ferritin but has an opposite effect to zinc(II), since it has a positive catalytic effect on the uptake of iron by ferritin [40]. Otherwise, some metalloproteins such as ceruloplasmin [41] or metallothioneins [42] are capable to respectively promote the uptake or the removal of iron from ferritin, the latter giving rise not only to the existence to free toxic iron(II) but also to putatively damaging free copper(I) or zinc(II) ions that were initially bound to it. Other biomolecules such as glutathione (GSH), xanthine oxidase and superoxide dismutase (SOD) have also been reported to interact with ferritin (cf. last paragraph of Section 7).

However, the study and analysis of the interactions between ferritins and all these biomolecules and metal ions, as well as their biological significance, has remained until now dispersed in the literature. In this sense, this review aims at collecting all the information now available about the influence of metals and biomolecules, basically metalloproteins, in ferritin iron uptake and iron release. It is our belief that this will provide a solid basis of knowledge from where to extract comprehensive conclusions and to build future prospects. In fact the scenario we 
try to draw does not center exclusively in iron in ferritin but in the "ferritin + metal or biomolecule" system, a landscape much more complex than the former, but probably more realistic in terms of physiological significance. Finally, we will try to focus on the importance and consequences of all the above-mentioned interactions in the brain. The uncontrolled release of iron, but also of other metal ions such as zinc or copper, all of them essential but of well established toxicity when in excess, has been revealed to have important consequences in the brain, mainly in neurodegenerative pathologies. Consequently, we are confident that the review and synthesis of all the current available data on this subject will shed light on the possible interpretation of the underlying mechanisms triggering these diseases as well as provide clues to succeed in the design of strategies for their amelioration.

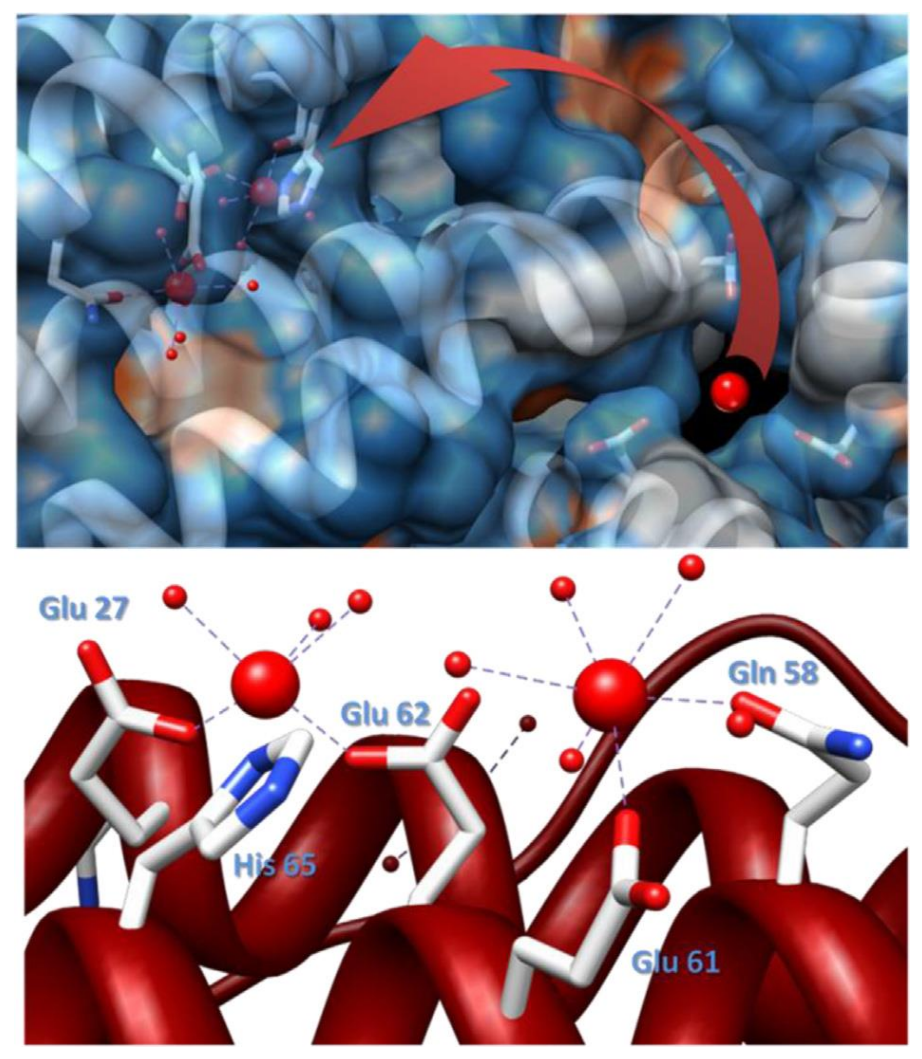

Fig. 2. The trip of iron(II) through the hydrophilic channel to reach the ferroxidase center (top). The two iron coordination sites at the ferroxidase center (bottom). 


\section{Ferritin iron uptake}

The process of iron uptake by ferritin has been extensively studied and reviewed [43]. Our purpose here is to briefly describe the chemistry of iron during its travel across the ferritin channels to the cavity, allowing the reader to envisage how the different steps that comprise the global ferritin iron uptake process can be affected by the presence of metals and metallobiomolecules.

The iron concentration in the cytosol is sensibly higher than that of any other transition metal. The reductive ambient of cytosol clearly favors the presence of iron(II) over iron(III), which leads to respective average values of $10^{-7}$ and $10^{-18} \mathrm{M}$ [44].

Iron(II)-citrate and iron(II)-thiol-containing biomolecules such as cysteine and glutathione seem to be the major components of the cytosolic iron pool [45]. The high concentration of glutathione in the cytosol (ranging between 2 and $8 \mathrm{mM}$ ) enables iron(III) reduction at physiologic pH. Iron(II) is then taken up by apoferritin, which is mainly located in the cytoplasm.

Iron(II) and other metal ions trafficking from the surrounding exterior to the ferritin cavity has been proposed to occur through the 3-fold channels [46]. Calculations of the electrostatic surface potential of ferritin identified a funnel of negative charge that would attract the iron(II), and other metal cations, toward the ferritin hollow [47]. In the most widely accepted model, iron(II) moves through the hydrophilic channels until observation a ferroxidase center of an H-subunit (Fig. 2) where it is catalytically oxidized by reaction with cellular oxygen [48] to form a diferric peroxo complex (DFC) [49,50], where iron atoms occupy two specific coordination sites (A and B).

Most of the structural information about the ferroxidase center has been inferred by a combination of kinetics and site-directed mutagenesis [51]. In the recombinant human $\mathrm{H}$-ferritin, the necessary amino acids include Glu27, Glu62 and His65 at site A, and Glu107, Gln141 and Ala144 at site B. The participation of some of these amino acids has been confirmed in the X-ray structure of the zinc(II) complex of the same recombinant ferritin (Fig. 2) [38]. 


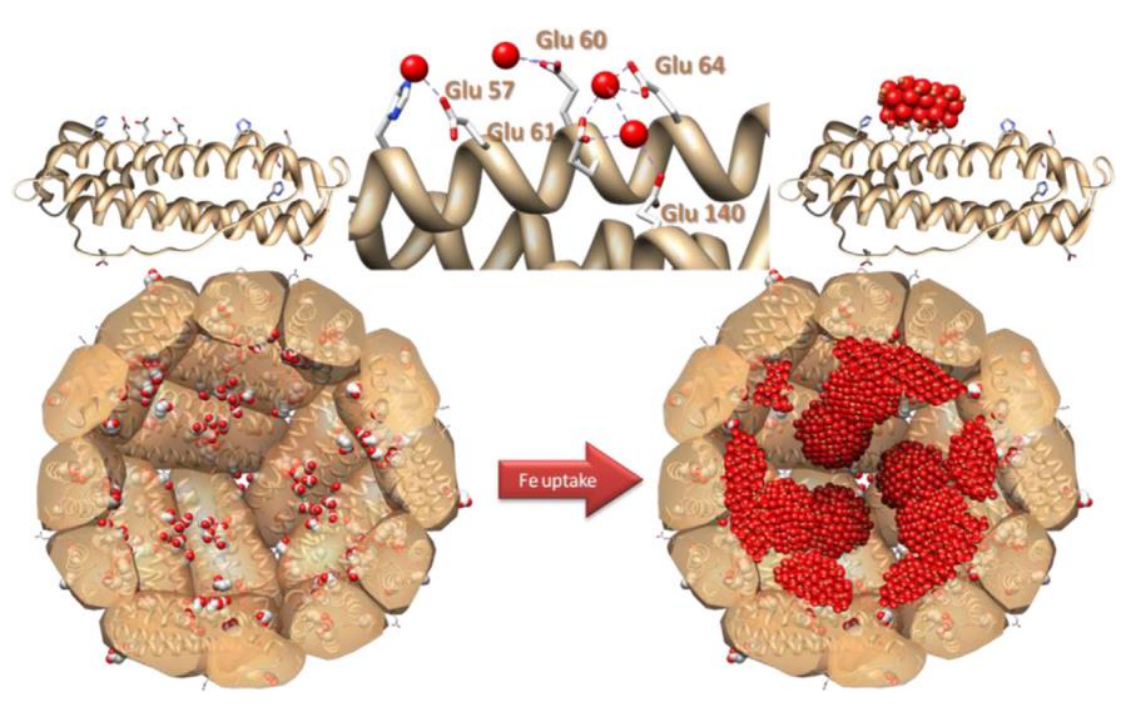

Fig. 3. Nucleation sites (top) and schematic representation of the formation of the first iron clusters. Ferritin core growth (bottom): from the nucleation sites to the final iron oxide nanoparticle

The structure of the ferroxidase center of ferritin from the hyper-thermophilic archaeal anaerobe Pyrococcus furiosus under aerobic conditions reported by Hagen et al. exhibits three iron atoms [52]: an iron site A appears to be the strongest affinity site since it is found occupied in the isolated protein, while sites B and C are found only occupied after soaking apobacterionferritin crystals in iron(II) solutions under aerobic conditions. The iron-iron distances between sites A and B vary between 2.6 and $3.6 \AA$ in the different subunits.

In another X-ray absorption spectroscopy study on eukaryotic ferritin, Theil et al. [53] described three different states that were trapped by rapid freeze quench of iron(II) ferritin reacting with $\mathrm{O}_{2}$ : an initial diiron(II) high-spin state, which is described with iron being in an average six-coordinate environment with a Fe-Fe distance of $3.44 \AA$, and a peroxodiron(III) intermediate with the very short Fe-Fe distance of $2.53 \AA$, which finally evolves toward a $\mu$-oxo/hydroxo diiron(III) species with a Fe-Fe distance of $3.00 \AA$.

An X-ray structure was reported for Escherichia coli bacterioferritin by Le Brun et al. [54]. The diiron species obtained by soaking under aerobic conditions, followed by flash freezing, was proposed to be in the reduced state. The iron coordination 
environment is contributed by one His and one Glu residue per iron and two bridging Glu residues. The iron-iron distance was 3.7 Å. Longer soaking times provided an iron center proposed to be a $\mu$-oxo/hydroxo diiron(III) species, with an intact coordination sphere and an iron-iron distance of $3.6 \AA$.

Recently, Bertini et al. reported the first X-ray picture of iron(III) products at the ferroxidase site in higher eukaryote ferritins [55] by flash freezing crystals of frog ferritin soaked during two different times in iron(II) solutions under aerobic conditions. The structure for long soaking times resulted in the observation of invariant diiron(III) sites with a Fe-Fe distance of about $3.1 \AA$, suggesting the presence of a $\mu$-оxo/hydroxo bridge between iron atoms. The electronic absorption spectra is typical of iron(III) ferritin in solution. The structure for short soaking times was investigated by using copper(II) instead of iron(II) to avoid oxidation. Two different copper(II) ions were found at sites $A$ and $B$ of the ferroxidase center with a $\mathrm{Cu}-\mathrm{Cu}$ distance of about $4.3 \AA$. While the coordination environment of copper at site A was similar to that of iron(III) in the structure for long soaking times, copper at site B also contains a bridging carboxylate but differs from that of site A because of the absence of bridging water/hydroxo and the additional coordination to the protein residue His54. Interestingly, His54 binding to metal ion had been observed in the cobalt(II) ferritin structure [46]. The authors hypothesized that the coordination of iron(II) at the ferroxidase center is similar to that of copper(II) and concluded that oxidation at the ferroxidase center requires changes in the coordination environment of iron(II) at site B and a parallel reduction in the metal-metal distance.

The path from the ferroxidase center to the cavity has been analyzed on the basis of a paramagnetic-NMR study [56]. Theil, Bertini et al. have proposed that the DFCs continue their travel to the cavity through the channels. In this journey, the DFC species interact between them to form multimeric iron(III) entities, which ultimately are fixed at the nucleation sites of the cavity and that initiate the growth of the iron core (Fig. 3).

In contrast to this model, Hagen et al. assume that core formation starts directly after formation of the ferroxidase center without occurrence of small clusters en route to core formation. Studies of this group on the $P$. furiosus ferritin suggest that the ferroxidase center, i.e. the invariant metallic motive constituted by iron atoms 
bridged by a peroxo group, which are permanently bound to specific amino acids of the protein, is a stable prosthetic group and that after formation of a stable diiron center, iron(II) is oxidized on its way to the core by the iron(III) in the ferroxidase center, and electrons are transferred to $\mathrm{O}_{2}$ [57]. EPR [58] and kinetic studies [59] support this assumption.

On the other hand, studies by Le Brun et al. on the mechanism of iron deposition in mammalian ferritins suggest an additional pathway based on a reaction on the mineral surface that would allow simultaneously the iron oxidation and nucleation steps [60,61]. Thus iron(II) could migrate through the 3 -fold channels and be directly oxidized to iron(III) on the surface of the mineral core.

Likewise, it has been traditionally considered that some oxo anions, in particular phosphate, increase the rate of iron core formation [62]. Ferritins from different origins contain phosphate that is associated with the iron core. In bacterial ferritin, the phosphate/iron ratio can be as high as close to unity [63], whereas a ratio of approximately 0.1 has been found in mammalian ferritins [64]. Recently, Watt et al. showed that phosphate inhibited iron loading into L ferritin, due to the lack of the ferroxidase center, whereas iron loading into $\mathrm{H}$ ferritin showed identical iron loading pattern in the presence or absence of phosphate [65].

In any case, analyzing all the literature data, it appears that although the ferritin uptake process has been extensively addressed, there is a limited knowledge of the mechanism of growth of the iron core at the ferritin cavity, and still much needs to be learned about how the iron core grows at the nucleation sites to yield the final nanoparticle. 


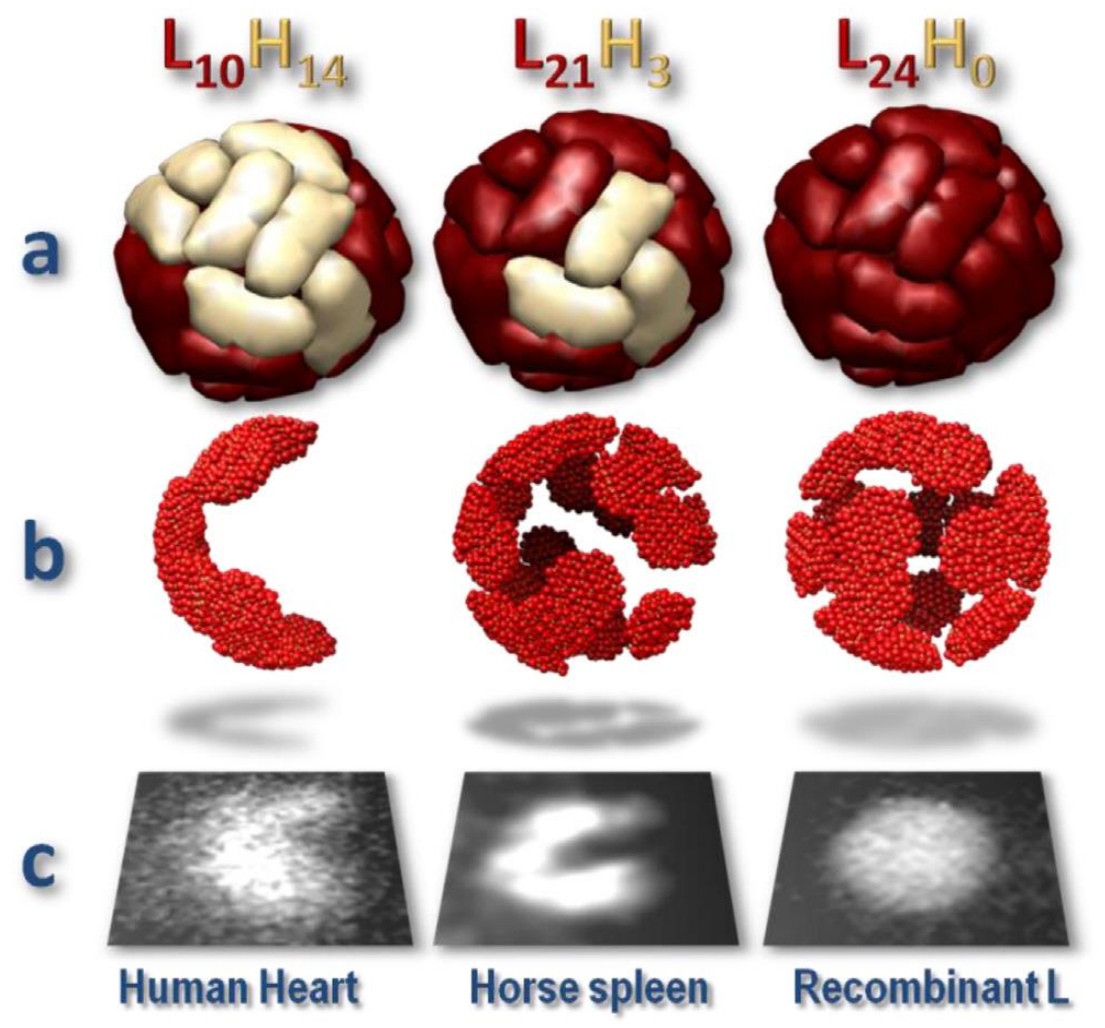

Fig. 4. (a) Structure of human heart, horse spleen and recombinant L ferritin. $L$ subunits are in red and $H$ in cream. (b) Modeled morphology of the iron core and its projection taking into account only $L$ nucleating subunits. (c) Experimental transmission electron microscopy HAADF-STEM images every ferritin, exhibiting expected morphologies after the 24-n model.

In this context, and after a transmission electron microscopy study of horse spleen, heart and recombinant $\mathrm{H}$ and $\mathrm{L}$ ferritins, we have recently proposed a new model for the ferritin iron core growth based on 24-n nucleation sites (where $n$ is the number of $\mathrm{H}$ subunits) [66]. This implies that only L subunits participate in the mineral growth with a nucleation center per subunit. The iron atoms nucleate at these 24-n sites, grow and connect to produce the final iron particle. The subtraction of some nucleation sites to the initial 24 subunits breaks the original cubic morphology and leads to the capability of reproducing other complex morphologies found in ferritins containing distinct combinations of $\mathrm{H}$ and $\mathrm{L}$ subunits (Fig. 4). 
From these studies, it is evident that the iron storing ability of a ferritin is mainly related to the number of its L subunits. This is in line with previous evidence that L-chain rich ferritins form iron particles of greater average size, crystallinity and magnetic order.

Bearing in mind the different stages that iron atoms wander from the entry into the ferritin capsid until reaching its cavity, it is reasonable to consider that the presence of some other metal cations than those of iron or some biomolecules could affect and/or alter the global process of ferritin iron uptake. In particular, three mechanisms could be envisaged: (i) some metal cations blocking the ferroxidase center, this avoiding the required iron(II) oxidation, (ii) some metal cations blocking the nucleation centers, this inhibiting the necessary nucleation of the multimeric iron(III) species to start the growth of the mineral core, and (iii) some biomolecules promoting the iron(II) oxidation, this facilitating the ferritin iron reconstitution. Specific literature examples of each of these three possible mechanisms of ferritin iron uptake alteration will be discussed in detail in the following sections. What is necessary to emphasize here is that the process of iron storage can be, and indeed is, affected by parallel metal metabolisms, either increasing or decreasing the iron uptake of ferritin. Therefore, the iron storage process must definitively be analyzed in a broader and more realistic scenario where metal trafficking - not only iron - should be analyzed as a whole. As an example of this approach, we have recently found out that an excessive proportion of $\mathrm{H}$ subunits in the ferritin capsid results in a significant decrease of the amount of stored iron with the consequent existence of free iron(III), which is not fixed in the nucleation sites and that in turn is capable to oxidize some metalloproteins, ultimately leading to the liberation of other metals such as copper(I) or zinc(II) [67]. This kind of processes, where different free metal ions are generated and released by a cascade process starting in a non-appropriate iron storage of ferritin are especially significant in the brain, where improper iron uptake by ferritin has been suggested to result in the progression of neurological diseases. Hence, Dobson and co-workers proposed that $\mathrm{AD}$ patients could have a dysfunction in the brain iron storage that occurs as a consequence of disrupted ferritin $\mathrm{H}$ and $\mathrm{L}$ chain synthesis [68]. 


\section{Ferritin iron release}

A detailed knowledge of the iron release process from ferritin is also crucial to understand how iron can be made available when it is required by the cell and because of the possible role of free iron(II) in oxidative stress and in the progression of neurodegenerative diseases.

At physiological conditions, iron is released by ferritin when the iron concentration in the cytosol decreases, either because it has been taken for cell metabolism or because the overexpression of ferroportin, which acts as an iron export pump. The in vivo mechanism of iron release from ferritin is still undetermined. However it has already been made patently clear that the ferroxidase centers of the $\mathrm{H}$ subunits, which are central to the mechanism of ferritin iron uptake as stated in the previous section, are not involved in iron release. Therefore, the ferritin iron uptake and the ferritin iron release processes utilize distinct pathways [69].

Four global models have been proposed to account for the ferritin iron release: (i) the existence of an equilibrium between the iron stored in ferritin and the iron in cytoplasm, (ii) the ferritin capsid degradation, (iii) the participation of a chaperone that would dock with ferritin and directly remove iron(III), and (iv) the existence on an electron donor biomolecule that would dock with ferritin to reduce the iron(III) of the ferrihydrite mineral and facilitate iron(II) mobilization, which would be chelated by a chaperone molecule outside the ferritin molecule (Fig. 5).

Although there is a lack of definitive evidence to support the reduction-chelation model (option iv above), this mechanism is thought to be the one that operates in vivo since some data seem to support this hypothesis more strongly than others. On the one hand, the well-known reducing nature of the intracellular environment provides molecules such as flavins, glutathione and ascorbic acid, which are capable of reducing the iron from the ferritin core [70]. Furthermore, in vitro studies show that the most efficient method to remove iron from ferritin is by reduction-chelation (Fig. 5) [71]. In fact, this is the strategy commonly used in the laboratory to produce apoferritin from ferritin, emptying the ferritin capsid of iron, frequently by using thioglycolic acid (TGA) as reducing agent and 2,2'-bipyridyl (bipy) or ferrozine (fz) as iron(II) chelators.

Direct chelation and mobilization of iron(III) from ferritin by iron biochelators 
(option iii above), as transferrin is, has been described to be too slow to take place in a physiologically relevant time scale [72]. Furthermore, ferritin is essentially an intracellular protein and does not seem reasonable to envisage a mechanism of iron release from ferritin by a plasmatic protein. Likewise, a genuine large hexadentate iron chelator such as desferrioxamine, a well known siderophore and a drug for iron chelatotherapy, extracts iron from ferritin albeit at a slow rate [73], probably because of the difficulties that this large molecule finds to pass through the narrow 3-fold ferritin channels. Only by using smaller and, in fact nonbiologically available iron(III) chelators, such as the aceto- and benzohydroxamate molecules, and in the presence of physiological concentrations of urea (reported as an agent able to open the ferritin pores [74]), complete removal of iron from ferritin can be achieved in $1 \mathrm{~h}$ at $\mathrm{pH} 7.4$ [75].

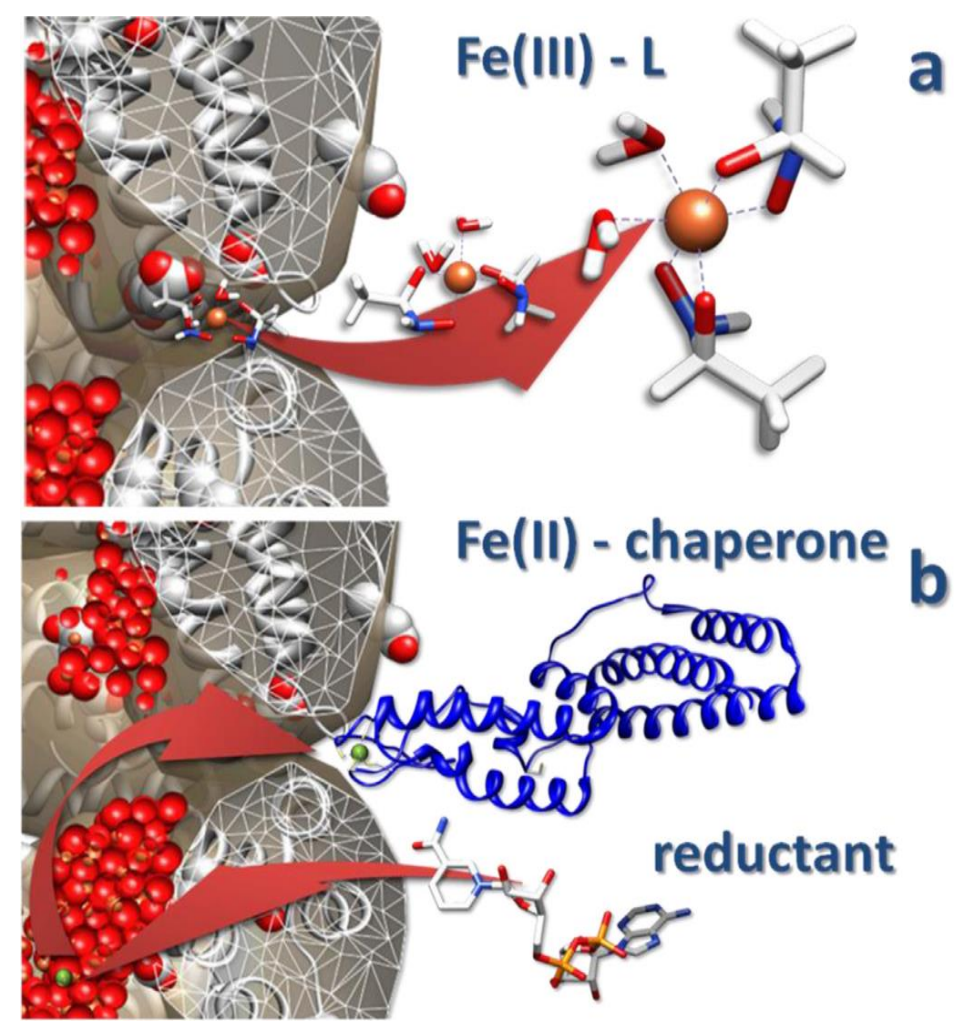

Fig. 5. Schematic representation of the two main mechanisms proposed for ferritin iron release. Top: direct chelation (model iii). A molecule (L) directly chelates iron(III) at the hydrophilic channels. Bottom: reduction-chelation (model iv). A reductant reduces iron(III) to iron(II), which leaves the ferritin and it is taken up by a chaperone. 
A route recently proposed by Bou-Abdallah et al., involving the release of iron from ferritin iron by triazine chelates, which are capable of rapidly mobilizing iron from ferritin, must be also considered. This way of iron release is catalyzed by oxygen and involves reduction of the iron core by the superoxide anion. The reduced iron diffuses out of the ferritin shell and forms iron(III) complexes with the concomitant production of superoxide anions [76].

Going deeper into the reduction-chelation mechanism, two general scenarios have been conceived depending on the size of the reductant. For biomolecules small enough to traverse the ferritin channels, the reaction would take place in the ferritin cavity, giving rise to iron(II) and the oxidized biomolecule. This route has been shown to occur when catechol and 6-hydroxydopamine (6-OHDA) react with ferritin $[77,78]$. Interestingly, the interaction of 6-OHDA and ferritin triggers a cycle of reactions that could sustain PD [79]. In this disease, the neuromelanin in the substantia nigra contains high iron levels, part of which could produce $\mathrm{OH} \bullet$ radicals via Fenton reaction. These can readily oxidize the neurotransmitter dopamine to the neurotoxic 6-OHDA, which is a strong reducing agent, and therefore is, in turn, able to release iron(II) from ferritin [79]. This cycle of events could well explain the development of PD due to continuous neuron damage.

For biomolecules significantly larger than the ferritin channels, it has been considered that the reduction of iron(III) to iron(II) could occur by electron tunneling, without direct physical interaction between the biomolecule and the ferritin iron core. In this sense, it must be noted that electron transfer proteins are capable of reducing the iron core of some ferritins, suggesting the existence of both a docking site and an electron transfer pathway through the protein shell of ferritin [80]. In some cases, this docking site has been discovered, as it occurs when ferredoxin specifically binds to the heme group of bacterial ferritin and opens electron transfer through the protein shell [81]. Likewise, a combination of computational modeling methods allowed showing how flavin molecules bind to the ferritin protein surface and transfer electrons across the protein shell reaching the iron core [82]. We also recently demonstrated that some metallothioneins can promote iron release from ferritin by pumping electrons through the shell that reduce iron(III) to iron(II), which diffuses into the intracellular milieu [42].

In any case, either if the reductant biomolecule traverses and contacts the ferritin 
core or if an electron tunneling process takes place, both options lead to the mobilization of iron(II), which finally diffuses through the ferritin channels into the cell cytoplasm, where it is able to participate in free radical-producing processes. Therefore, when cells require iron from ferritin, more than a reductive biomolecule is needed because, in order to prevent the formation of ROS from free iron(II), a metallochaperone or an iron(II) chelator is also necessary to rapidly bind and sequester the liberated iron(II) [83].

If we do accept that the ferritin iron release takes place in the cell through a controlled reduction-chelation mechanism, it is also reasonable to consider that it could be affected and/or altered by the excess, or default, of some biomolecules. In particular, two possibilities could be envisaged: (i) the excess of the reductant, which would give rise to an uncontrolled reduction of iron(III), and consequently to an uncontrolled iron(II) delivery, and (ii) the absence or default of the chaperone, necessary to capture the released iron(II), and prevent ROS formation. The implications and consequences of these two possibilities of ferritin iron release alterations will be extensively discussed in the following sections.

\section{Iron and ferritin in the brain}

As it has been previously stated, iron is essential for life, and in the brain is important for neuronal development, gene expression, enzyme function, dopamine, heme and iron-sulfur cluster synthesis as well as in electron transport [84-86].

More rigorous and definitive data are still needed to know the exact map of the distribution of iron and ferritin within the brain. The huge amount of data that can be found in the literature are often contradictory [87]. However, it is now accepted that the iron amounts in substantia nigra, a small nervous structure of about 500 mg located bilaterally in mesencephalon, which produces the dopamine neurotransmitter, and hippocampus would be close to $200 \mathrm{ng} / \mathrm{mg}$ and $50 \mathrm{ng} / \mathrm{mg}$, respectively. It is accepted that $\mathrm{PD}$ is caused by a progressive degeneration of nervous cells located in substantia nigra, whereas AD is provoked by the death of nervous cells in hippocampus. The reason for the degeneration of neurons in substantia nigra in PD remains unknown at present, although it is noteworthy that 
large concentrations of iron, comparable to those in the liver, are found in this brain compartment of PD patients. In fact, Youdim et al. formulated the hypothesis that PD is a progressive siderosis of substantia nigra, which enhances the oxidative stress [88]. Controversy of about one order of magnitude in the iron levels measured in neurological disorders and controls have been excellently reviewed by Galazka-Friedman and Friedman [87]. However, as stated by the authors, it is still possible that iron is involved in the pathogenesis of neurological disorders, as even minor changes in the amount and form of iron may initiate the processes leading to cell death. In any case, it is striking that the iron level in human brain increases linearly with age, reaching a plateau in substantia nigra at forty, because it is precisely at this age when neurological episodes begin. Furthermore, the local excess of iron occurs at the site where neurodegeneration develops and where specific protein aggregation occurs. This evidence suggests that an increased concentration of iron, even subtle, in the tissues contributes to generate oxidative stress.

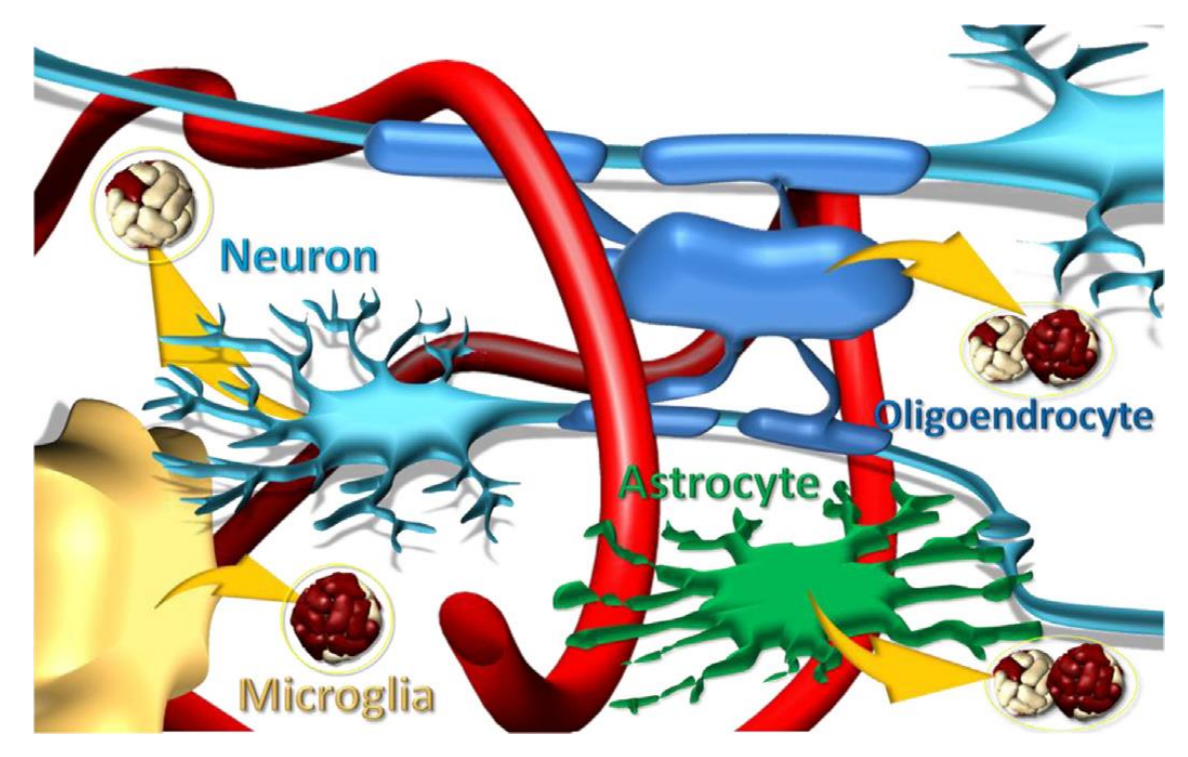

Fig. 6. Predominant ferritin type (H-or L-rich) in neuron and glia

Nevertheless, it is also true that the question whether iron accumulation might be an initiating factor of these diseases or whether it occurs as a consequence of 
impaired metabolic processes has not found an answer yet. Similarly, the question where the excess of iron comes from is also unsolved. However, whatever the origin would be, high levels of free iron are toxic owing to the formation of ROS that finally lead to neuronal death [89]. Also, the pathologic aggregation of proteins seems to be modulated by iron [90-92].

Both total brain and substantia nigra iron is stored in ferritin [93-95]. Ferritin is also highly synthesized within the glial compartment, predominantly in oligodendrocytes, microglia and astrocytes [96] (Fig. 6). Under normal conditions, most of the iron in the brain is safely stored, and there is no need for a substantial increase of the total amount of iron(II) to provoke an increase of the amount of free radicals. Therefore, a minimal ferritin disorder could justify a degeneration of the nervous cells.

As it occurs in the distribution of $\mathrm{H}$ - and L- ferritin content throughout the body, the $\mathrm{H} / \mathrm{L}$ ferritin ratio varies in the different regions of brain in agreement with the requirements of every cell type to detoxify or store iron [97]. H-rich ferritin is found mainly in neurons whereas L-rich ferritin is more abundant in microglia [98]. Both, H- and L- ferritin subunits are synthesized in oligodendrocytes and astrocytes [99] (Fig. 6). Furthermore, the concentrations of $\mathrm{H}$ - and L-ferritins in the substantia nigra increase during life, probably a protective response to the increase of iron with age. The distribution of types of ferritin within substantia nigra, especially the presence of H-rich ferritin in neurons and L-rich ferritin in glia agree with the protection role of $\mathrm{H}$-ferritin against the cytotoxic effect of iron(II) and the storage capability of L-ferritin.

Hippocampus is a part of the temporal lobe cortex, which plays a crucial role in memory. Its atrophy with the decline in the number of nervous cells is the starting point of $\mathrm{AD}$. The cause of this neurodegenerative disorder also remains unidentified, although it seems that iron mediated oxidative stress may play a role.

Galazka-Friedman [100] reported that the Mössbauer spectroscopic pattern of hippocampus samples and that of ferritin were highly coincident, as it happened with that of substantia nigra. The only difference in these spectra was the intensity of signals, which reflects different iron concentrations in the two brain areas. The average size of iron cores of ferritin in the hippocampus measured by electron 
microscopy was about $3.1 \mathrm{~nm}$. In agreement with previous studies reported by our group [66], which correlate size and morphology of the ferritin core with shell composition, this small size should correspond to a high content of H subunits, in agreement with ELISA studies that revealed a higher average concentration of $\mathrm{H}$ ferritin $(150 \pm 30 \mathrm{ng} / \mathrm{mg})$ than $\mathrm{L}$ ferritin $(20 \pm 10 \mathrm{ng} / \mathrm{mg})$ on the same type of samples [100].

The complex distribution of ferritin in the brain and the subtle balance in the appropriate composition of $\mathrm{H}$ and $\mathrm{L}$ chains show that ferritin can be a key component in brain function.

\section{Copper, zinc and related biomolecules in the brain}

Since iron uptake and release by ferritin shells is likely to be influenced, when non disrupted, by excess of other significant metal ions in brain cells or their subcellular compartments, it is worth catching a glimpse into the incidence of $\mathrm{Zn}(\mathrm{II})$ and $\mathrm{Cu}(\mathrm{I}) /(\mathrm{II})$ in mammalian organisms, and precisely, in mammalian brain cells. $\mathrm{Zn}(\mathrm{II})$ is present in the brain at large amounts $(10 \mu \mathrm{g} / \mathrm{g})$ [101]. Most of this zinc accumulates inside cells, where it can reach cytosolic concentrations up to 150 $\mu \mathrm{M}$, as in neurons [102,103] (Fig. 7), in contrast with the $0.15 \mu \mathrm{M} \mathrm{Zn}$ (II) typical of central nervous system (CNS) extracellular fluid and serum [102]. Despite these impressive amounts, free $\mathrm{Zn}$ (II) is a minimal percentage of total $\mathrm{Zn}(\mathrm{II})$, hardly reaching levels above $1 \mathrm{nM}[104,105]$. This implies that, in physiological conditions, most of the brain $\mathrm{Zn}(\mathrm{II})$ is coordinated to some biomolecule, mainly proteins and other smaller compounds [106-108]. Most of the pool brain $\mathrm{Zn}$ is highly role-specific, being related to neuronal intracellular signaling and neurotransmission [109]. Noteworthy, the so-called zinc-enriched neurons (ZEN) accumulate $10-15 \%$ of the total brain $\mathrm{Zn}$ (II) confined in their presynaptic vesicles (Fig. 7) [110]. Pathologies that lead to abnormally increased synapsis rate (ischemia, epilepsy) supposes an excessive postsynaptic uptake of $\mathrm{Zn}$ (II) followed by a massive accumulation of intracellular free $\mathrm{Zn}$ (II) that, at the end, directly provokes neuronal death or takes part in other undesirable

processes by interacting with biomolecules such as ferritin. When $\mathrm{Zn}$ (II) reaches levels that would compromise cell functionality and viability [111,112], it is 
translocated into specific cell compartments (mitochondria in neurons), or sequestered by buffering peptides in the cytosol, mainly metallothioneins (MT) [113]. MTs are small (6-10 kDa), cysteine rich (33\%) metalloproteins that bind a wide spectrum of heavy metal ions. They are major players in the homeostasis of physiological $\mathrm{Zn}(\mathrm{II})$ and/or $\mathrm{Cu}(\mathrm{I})$, as well as in metal detoxification processes. The mammalian MT system includes four highly similar MT isoforms (MT1-MT4, the latter not present in the brain), which are 60- to 68-amino acid peptides with fully conserved Cys motif distribution. The tissular expression pattern of the four MTs shows substantial differentiation. Hence, MT1 and MT2 are ubiquitous, highly inducible isoforms that respond to a considerable number of factors mainly metal overload and oxidative stress. In CNS, MT1/2 are predominantly synthesized in astrocytes and microglia, both in gray and white matter [114], and have been widely associated with the prevention and healing of CNS inflammation and injuries, being greatly induced under these conditions. MT3, the brain-specific isoform, first identified as a growth inhibitory factor (GIF) [115], is constitutive in neurons (prominently hippocampal neurons), some glial cells and in the extracellular brain space [116], and it appears mainly involved in neuronal growth and survival regulation, and, significantly, in processes localized in axon and dendrite interfaces, as the same synaptic transmission. A recent review of protein interactions in which MT is involved highlights the role of the different MT isoforms in the brain $\mathrm{Zn}$ (II) secretion and recirculation events [117]. Although $\mathrm{Zn}$ (II) is a redox-inactive ion, the zinc- thionein/thionein cycle, besides preventing deleterious free $\mathrm{Zn}(\mathrm{II})$ concentrations, provides an indirect pathway of redox buffering mechanism through the thiol/disulfide equilibrium of their abundant cysteine residues [118]. Finally, it is worth noting that the tripeptide glutathione (GSH) has also been shown to thwart the toxicity caused by excess zinc, most probably by direct chelation, so that in emergency situations, a considerable amount of Zn-GSH complexes is likely to be present in brain cells [119]. 


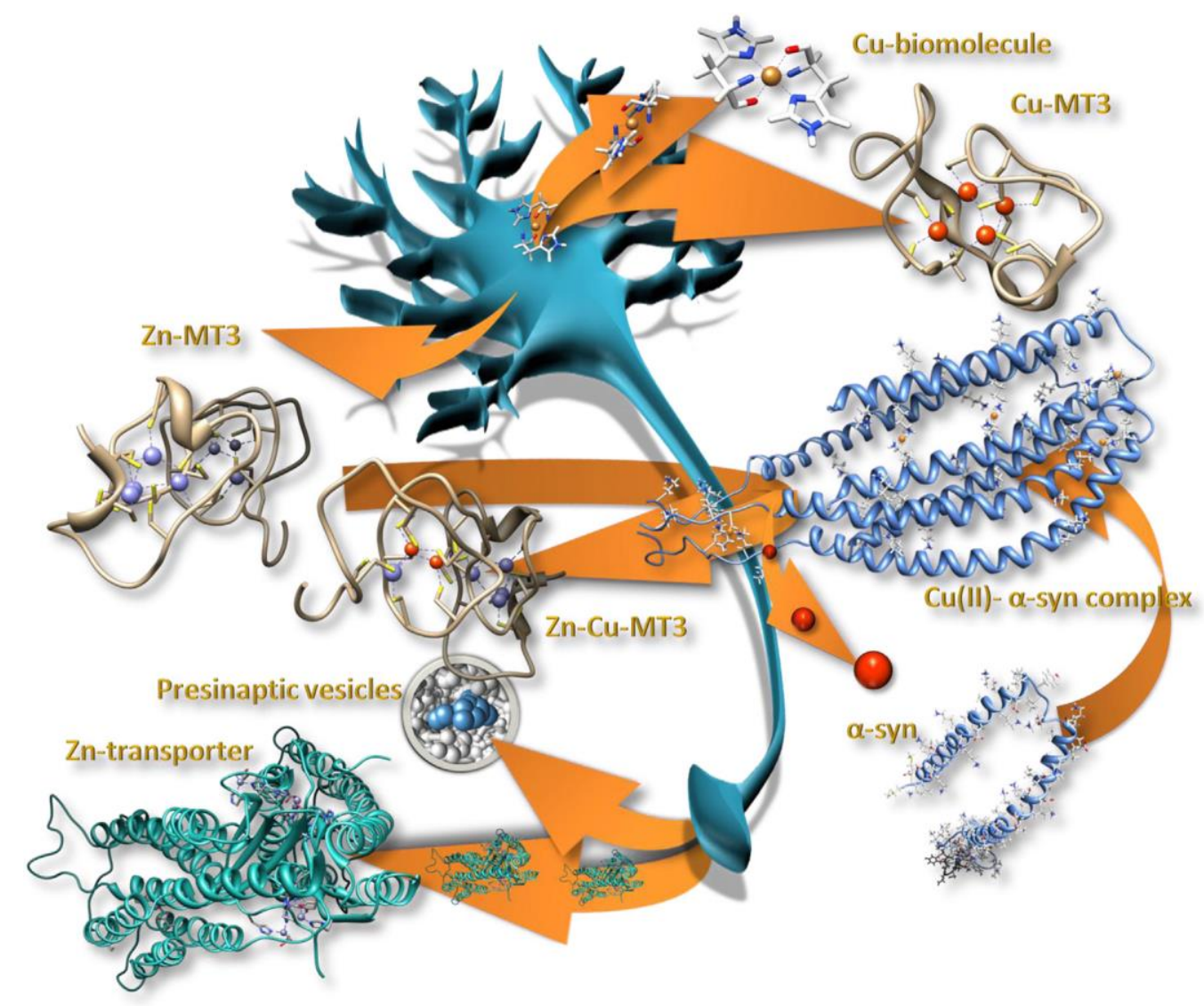

Fig. 7. Zinc- and copper-containing biomolecules in neurons. In the absence of $3 D$ structures of the distinct metal-MT3 species, the drawings included in this figure just represent the presence of these complexes in neurons and do not have any structural value.

In contrast with zinc, and despite the fact that copper is also a catalytic cofactor in crucial enzymes, its content per adult body is less than $110 \mathrm{mg}$ (cf. $3 \mathrm{~g}$ for $\mathrm{Zn}(\mathrm{II})$ ), and in the brain it does not exceed 9-10 mg approximately [120]. Free $\mathrm{Cu}$, being redox active, is extremely dangerous for cells, and therefore cells avoid deleterious effects by maintaining the levels of free $\mathrm{Cu}^{2+}$ lower $\tan 10^{-18} \mathrm{mM}$ [121]. $\mathrm{Cu}$ is far from being equally distributed in the brain, and e.g. substantia nigra accumulates twice as much $\mathrm{Cu}$ as the surrounding brain regions (Fig. 7) [122]. Copper in the brain is mainly associated with holoenzymes, transporters and chaperones, and homeostatic proteins [123]. Cu-containing enzymes are mainly involved in cell respiration, iron metabolism, ROS defense mechanisms, and significantly, the synthesis of neurotransmitters (dopamine [124]) and neuron myelinization [122]. 
Copper is mainly transported in blood bound to ceruloplasmin (CP), although minor amounts are also coordinated to albumin. In the frame of this review attention has to be drawn to the membrane anchored CP reported in astrocytes [125], due to its ferroxidase activity. Brain cells, and especially neurons, avoid excessive intracellular copper by pumping it out to the cell membranes or supposedly by sequestering it into MT complexes, although the knowledge on brain $\mathrm{Cu}-\mathrm{MT}$ and their behavior is far more limited than that of Zn-MT. It is obvious that direct deleterious effects of $\mathrm{Cu}$ in the brain by ROS generation (Fenton reaction) derived from its redox nature are effectively avoided by MT coordination. But the most fascinating aspect of $\mathrm{Cu}$ ions in the brain concerns the increased evidence about their involvement in the onset and progression of neurodegenerative disorders as $\mathrm{AD}, \mathrm{PD}$, amyotrophic lateral sclerosis (ALS), and transmissible spongiform encephalopathies (TSEs) (for excellent recent reviews, see $[18,21])$. All these disorders are triggered by the aggregation of misfolded monomers and subsequent formation of insoluble deposits that accumulate in the brain, of the respectively associated proteins: the Aß-peptide, $\alpha$-synuclein, SOD and the prion proteins. In all these cases, interaction of Zn(II)-MT3 with the aggregation-prone $\mathrm{Cu}$-loaded peptides seems to preclude their harmful effects. Precisely, it has been shown that the interaction of Zn7 -MT3 and Cu(II)-Aßpeptides or $\mathrm{Cu}(\mathrm{II})-\alpha$-synuclein triggers a metal swap reaction which eliminates $\mathrm{Cu}(\mathrm{I})$ from the brain peptides and generates $\mathrm{Zn}, \mathrm{Cu}-\mathrm{MT} 3$ species with four $\mathrm{Cu}(\mathrm{I})$ ions bound to a partially oxidized MT3 domain, and the four Zn(II) ions remaining in the domain [126,127]. Therefore MT3 in brain metal homeostasis appears far from acting just as a mere reservoir of metal ions, becoming instead a key controller of redox reactions and, indirectly, of metal-induced protein damage, misfolding and aggregation.

\section{Interaction of ferritin with metal ions}

Iron-, zinc- and copper-handling proteins, as well as the metabolism and homeostasis of these physiological metal ions, are intimately related in all organisms. As an example, mutations in the genes controlling the multi-copper ceruloplasmin protein have been associated with iron overload diseases in humans [128]. People with low levels of ceruloplasmin have been shown to have increased 
iron deposits in various tissues [129]. Therefore, it seems reasonable to assume that in the framework of the interaction between iron, copper and zinc metabolisms, the ferritin protein could play a central role.

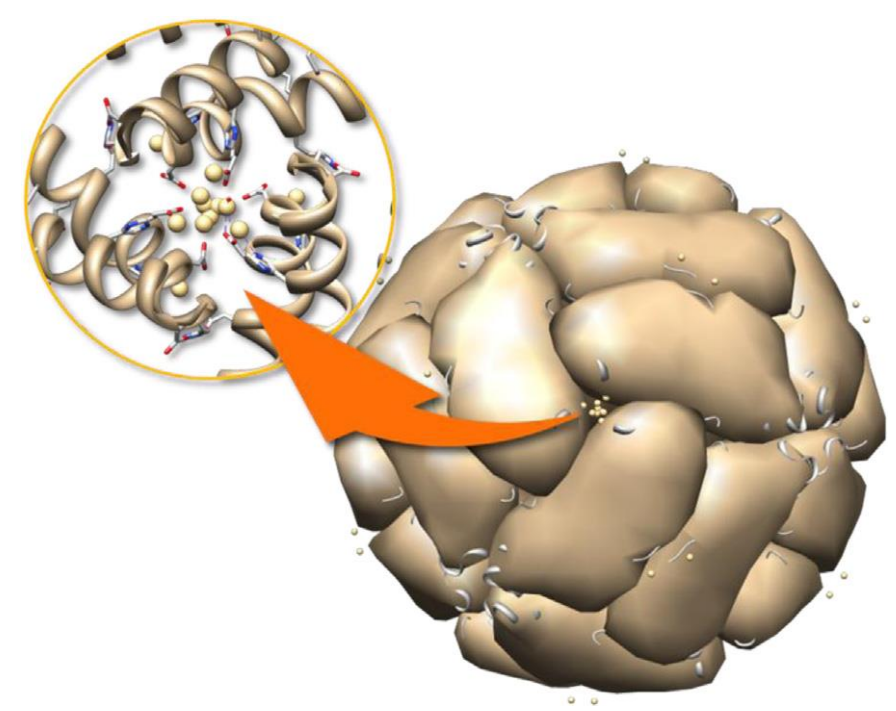

Fig. 8. Structure of the cadmium(II) apoferritin (Protein Data Bank file: 1AEW) [10]. Cadmium(II) concentrates preferentially around the entry of the C3 channels.

This statement could have sense when taking into consideration the higher iron levels, in most tissues, with respect to those of copper and zinc, but also because of the huge number of iron atoms confined inside ferritin, a situation that does not occur in the case of copper or zinc, this multiplying the consequences of any dysfunction taking place in ferritin owing to the amount of free and toxic iron that can be released.

The interaction of ferritin with metal ions has been extensively studied in order to gain a better understanding of the interactions and/or interferences that the later can cause in ferritin function, either in the iron uptake or iron release processes. Different studies provide evidence that metal cations are bound by ferritin [28] usually in two separate types of sites of very different binding constants. These two classes of binding sites are localized either within the cavity or at the external shell [28]. Interestingly, the largest number of binding sites is for divalent metal 
cations, although some of them are functional and others are nonspecific and do not play any decisive role in the genuine properties of ferritin.

Among the metals studied in the literature, we have considered here those that have a well-described role on the ferritin function as well as a biological relevance, especially at brain level, i.e. cadmium(II), zinc(II) and copper(II). Zinc(II) and cadmium(II) cause inhibition of iron uptake by ferritin [130]. Before any iron fills a ferritin capsid, all metals compete for the iron binding sites during iron reconstitution. Once the iron core starts formation, metal ions alter the ferritin function by a different mechanism, some of them inhibiting, other promoting the iron core growth.

Cadmium(II) binding is diminished by the presence of a ferritin core, clearly pointing out that cadmium(II) compete with iron(II) for the same sites inside the ferritin shell. In fact, when the ferritin cavity is empty, up to $24 \mathrm{Cd}(\mathrm{II})$ can be bound to its inner surface, one per subunit [28]. However, the mechanism by which cadmium(II) affects the ferritin iron reconstitution is not only based on the competition for iron binding at the cavity level, but also lies in the fact that cadmium(II) strongly binds other nonspecific sites, especially at the external shell surface. There, cadmium(II) has probably the greatest affinity for these sites, and is able to exclude almost all other metals from binding. It should be noted that cadmium binds sites localized around the entry of the hydrophilic channels (Fig. 8), and that it may even hinder the entry of other metals, including iron, and therefore block the ferritin iron reconstitution. Based on the interaction with the ferritin shell and on the effect that this interaction provokes in the solubility of the ferritin protein, cadmium(II) is commonly used as a precipitant agent of ferritin [131] and in fact, most commercial ferritins contain significant amounts of cadmium coming from the preparation process. 


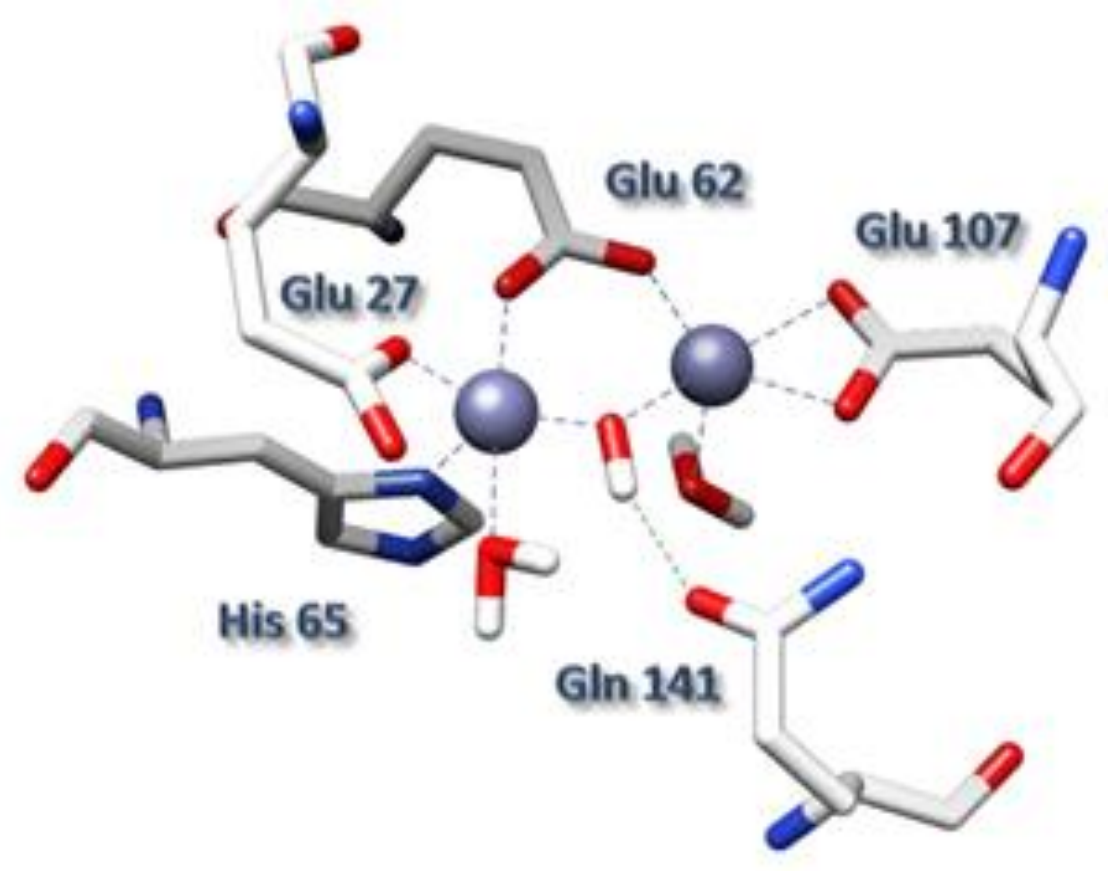

Fig. 9. Modeled dizinc ferroxidase complex based on crystallographic data [132].

As stated throughout the review, iron uptake by ferritin involves the oxidation of two iron(II) located at the highly conserved ferroxidase centers of the individual $\mathrm{H}$ subunits. The role of these centers therefore appears to be essential for the iron(II) oxidation catalysis and the subsequent ferritin core formation by nucleation at the L-subunits. Studies on iron oxidation by mammalian, bacterial, and archaeal ferritins have indicated that different mechanisms can be operative in the zinc(II) inhibition of the iron core formation, taking into account that $\mathrm{H}$-ferritin ferroxidase activity is inhibited by zinc(II) [128].

In human H-chain ferritin, two main types of $\mathrm{Zn}$ (II) binding sites have been described: at the entrance of the eight C3 channels and at the ferroxidase site of the protein. The kinetics and binding data indicate that the binding of zinc(II) in the three-fold channels, which is the main pathway of iron(II) entry in ferritin, blocks the access of most of the iron to the internal ferroxidase sites, which accounts for the inhibition by these metal ions of the oxidative deposition of iron in ferritin.

Zinc(II) has been assumed to be the best iron(II) substitute for structural determination purposes because it is redox stable, and because both ions are similar in size and are moderate Lewis acids. Hence, the structure of recombinant 
human $\mathrm{H}$ dizinc(II) ferroxidase complex has been solved by X-ray crystallography (Protein Data Bank file 2CEI) [38]. A perspective view of this is displayed in Fig. 9. The zinc at site $\mathrm{A}$ is coordinated to a nitrogen atom from His65 and three oxygen atoms, two from Glu27, Glu62 and the third one presumed to be from a water molecule. The zinc at site B is coordinated by both carboxylate oxygen atoms of Glu107 and Glu62, which bridge the two metal sites. Furthermore, a computational study identified a hydroxide bridge between sites A and B, and another water molecule at site $B$ and showed that no other ligand or peripheral molecules are present in the experimental dizinc ferroxidase center [132]. Finally, and according to these authors, the modeled structures of the diiron and dizinc complexes are close, suggesting that the dizinc ferroxidase is an accurate model of the native diiron complex.

Although the empty ferroxidase site accommodates two zinc(II) ions, the binding of just one zinc(II) is enough to abolish the iron(II) oxidation capability of the ferroxidase center [57]. It is interesting to note here that zinc(II) binds relatively tightly to horse spleen apoferritin, displacing iron(II) under anaerobic conditions but however, once the ferroxidase center is filled with two iron(III), zinc(II) is no longer able to bind there, nor does it inhibit the iron core formation. A similar situation has been described for cadmium(II). Therefore, the existence of a competition between metals for different apoferritin binding sites takes place but once the ferritin biomineralization process is triggered neither cadmium or zinc are able to affect the ferritin machinery.

Interestingly, in the case of the recombinant human H-ferritin, the structure of the distinct complexes with zinc(II) reveal a surprising similarity between them, indicating that the dinuclear site in this recombinant ferritin is quite a rigid site for this metal ion. Surprisingly, this is not the case when iron occupies these same binding sites. As previously described, coordination of iron at the ferroxidase center undergoes changes during oxidation with the subsequent iron-iron distance shortening [55].

The rigidity of the zinc(II) coordination at the ferroxidase site with respect to the flexibility found for iron is probably a consequence of the non-redox chemistry of zinc(II), which has a definitive importance in how zinc(II) affects the ferritin iron uptake. This is more evident when the coordination of copper to the ferroxidase 
center and its effect to the ferritin function is analyzed (see below).

The lack of ferroxidase activity in ferritin due to the presence of zinc(II) is extremely relevant in neurons, where the concentration of zinc(II) becomes very significant (Section 5) and the ferritin is predominantly H-rich (Section 4). A minimum amount of free zinc(II) could inhibit the appropriate iron(II) oxidation by ferritin, giving rise to a cascade radical process that would conclude with neuronal death.

Furthermore, the interaction of zinc(II) with ferritin can be extrapolated to other neurological scenarios. For instance, $\mathrm{AD}$ is complicated by prooxidant intraneuronal free iron(II) and, interestingly, by zinc(II) overloading within amyloid plaque. Interestingly, the $\mathrm{AD} \beta$-amyloid protein precursor has been described to exhibit ferroxidase activity due to the existence of what Bush et al. denominate a $\mathrm{H}$-ferritin-like active site, which is captivatingly also inhibited by zinc(II) [133]. However, it must be taken into account that the ferroxidase activity of the AD $\beta$-amyloid protein precursor has been recently called into question and asked for its revaluation [134].

The interaction of copper with ferritin has also been investigated. Copper(II), as in the case of zinc(II), was shown to bind relatively tightly to horse spleen ferritin. Once bound, copper(II) has a catalytic effect on the aerobic oxidative uptake of iron(III) by ferritin, which means that it induces an opposite effect to that of zinc(II). The difference between the effect of zinc(II) and copper(II) has been explained by Moore et al. in terms of the capability of copper(II) to take part in redox reactions [40]. In the absence of any other metal ions, two iron(II) bind at this site, are oxidized by $\mathrm{O}_{2}$ and form the DFC. Now, returning to the opposite effects of zinc(II) and copper(II) in horse spleen ferritin, it is plausible to consider that if these two ions are bound in a way that they occupy just one end of the site, an incoming iron(II) occupying the other end might be oxidized by copper(II) but not by zinc(II). The iron(III) produced could then migrate from the site to allow another iron(II) to take its place alongside the produced copper(I). At this point a two-electron reduction of $\mathrm{O}_{2}$ would generate copper(II) and iron(III) and, with the migration of iron(III) away from the site, the cycle could be reinitiated [40]. Unfortunately, only crystal data of ferritin-copper(II) and not copper(I) complex are yet available to confirm this hypothesis, but it should be highlighted that, as 
stated before, both the distances and bond angles found for the zinc(II) complexes of ferritin point out to an extreme rigidity of the site that would justify a zinc inhibitory role of the ferroxidase activity, but a promoting role for copper.

The loss of the ferroxidase activity of ferritin in the brain becomes a transcendent problem when pathological iron(II) accumulates and neurodegenerative processes are triggered. It is quite intriguing to realize that the presence of free, and toxic iron(II), can be generated either by an excess of zinc that inhibits the ferroxidase activity of ferritin, or by a deficiency of copper. In fact, when copper lacks, there is also a malfunction of the multicopper ferroxidase ceruloplasmin protein and a development of the aceruloplasminemia disease, which leads to glial iron accumulation and dementia.

\section{Interaction of ferritin with metalloproteins and other biomolecules}

Two metalloproteins, specifically $\mathrm{Cu}$ - or Zn-containing proteins, have been reported in literature to somehow interact with ferritin: ceruloplasmin, a blue multicopper oxidase with ferroxidase activity [135], and metallothioneins (see Section 5).

The oldest studies, carried out before the 2000 decade, called into question the mechanism of ferritin iron uptake described before in this review, and which is nowadays universally accepted. Aust and coworkers defended, at the end of the 90s, the docking between ceruloplasmin and ferritin [41]. This research group was defending that the ferroxidase activity of the H-subunits was leading to iron loaded ferritins with properties notably differing from those of native ferritins. In parallel, they reported that the enzymatic load of apoferritin with iron by using intact human ceruloplasmin rendered iron loaded ferritins with nearly identical properties to those of native ferritins [136]. Therefore, to accomplish the iron(II) to iron(III) oxidation by ceruloplasmin, a protein-protein complex formation was hypothesized, and the existence of a specific recognition site for the interaction of both proteins and the stimulation of its ferroxidase activity was suggested. In fact, the symptoms of iron overload as well as of excessive deposition of insoluble iron found in patients diagnosed with aceruloplasminemia (low concentrations of active ceruloplasmin) or Menkes disease (a disorder that affects copper levels in 
the body, leading to copper deficiency) supported the proposed interaction. Unfortunately, this research line was stopped and no further data giving continuity to this hypothesis have ever been reported.

Much more recently, our groups reported an intriguing interaction between metallothionein and ferritin. Two proteins apparently designed by nature to protect cells, and organisms, from free transition metal ions, and to respectively maintain the homeostatic levels of $\mathrm{Zn}$ and $\mathrm{Cu}$, and Fe generated deleterious effects when observation each other. This serendipitous discovery occurred during the search for a biomolecule able to capture the released iron(II) from ferritin and thus capable to prevent ROS formation (Section 3 of this work). For this study, the Zncomplexes of the mammalian metallothionein isoforms found in the brain, MT1, MT2 and MT3 (Section 5), and the model horse spleen ferritin where chosen. The obtained results were astonishing (respectively 55.6, 23.9, and 59.5\% of iron release) and they correlated well with the $\mathrm{Zn} / \mathrm{Cu}$-thionein character of the assayed MTs [137]. Further experiments carried out either with $\mathrm{Cu}$-loaded or $\mathrm{Zn}, \mathrm{Cu}$ heteronuclear complexes of these MTs confirmed parallel behaviors and suggested that not only iron(II) and zinc(II), but also copper(I) can be liberated to the media if ferritins and metallothioneins meet in the cell [authors' unpublished results]. Interestingly, neither binding between the two participant proteins nor a disruption of the ferritin structure was detected during the interaction. However, iron and zinc liberation from their respective metalloproteins was reported to be the consequence of the oxidation of the cysteinic residues of the MTs. Therefore, a proposal of a tentative redox reaction between the two biomolecules by electron transfer through the ferritin shell was proposed owing to the size of the Zn-MT complexes, which impairs them reaching the mineral by traversing the protein shell through the ferritin channels (Fig. 10). Recent theoretical studies [82] and experimental observations [138] commented above give nowadays further support to this proposal. 


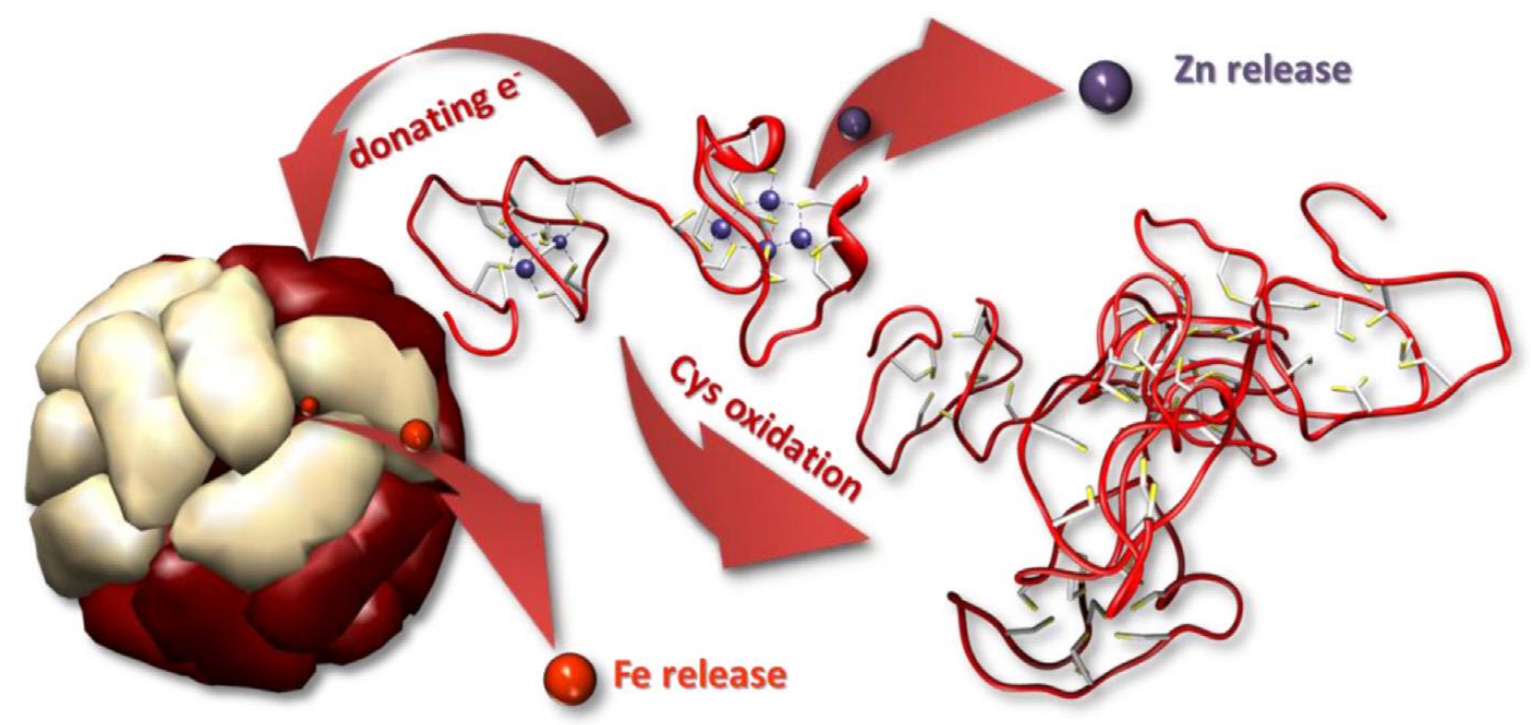

Fig. 10. Iron removal from horse spleen ferritin by mammalian Zn-MTx ( $x=1,2$ or 3$)$ takes place with simultaneous liberation of iron(II) and zinc(II).

The interaction of ferritin with multiple biomolecules, not strictly metalloproteins, has also been reported in the literature. Two groups can be differentiated depending on the result of these interactions: those that are thought to retrieve ferritin form circulation, and those that are proposed to serve the upload or release process of iron into or from ferritin. Here we will concentrate only in biomolecules that are present in the brain. The first group includes a variety of ferritin-binding proteins identified in mammals: H-kininogen, alpha-2macroglobulin, fibrinogen, and apolipoprotein B (ApoB) [139,140]. All these proteins are present in the brain and have been proposed to form complexes with ferritin to most likely remove it from circulation. High-molecular-weight kininogen (KNG) is a central constituent of the contact-kinin system, which represents an interface between thrombotic and inflammatory circuits and is critically involved in stroke development [141]. Alpha2-macroglobulin (alpha(2)M) is an abundant plasma protein similar in structure and function to the so called alpha2macroglobulin, which is also produced in the brain where it binds multiple extracellular ligands, being then internalized by neurons and astrocytes. In the brain of $\mathrm{AD}$ patients, alpha(2)M has been localized to diffuse amyloid plaques [142]. The blood protein fibrinogen, which leaks into the CNS immediately after blood-brain barrier disruption or vascular damage, serves as an early signal for the 
induction of glial scar formation via the TGF- /Smad signaling pathway [143]. At least two mechanisms of interaction between these proteins and ferritin have been proposed [140]: one is direct binding, such as that proposed for H-kininogen, and fibrinogen; the other is an indirect binding through heme on the surface of the ferritin molecule, such as that described for the heme-binding protein, ApoB. In this case, some distinctions should be made: those biomolecules supposed to contribute to the uptake process and those involved in the release of iron from ferritin. Some fatty acids appear to achieve the first goal, while, SOD and xanthine oxidase and cytochrome P-450 seem to fulfill the second purpose. Arachidonic acid (ARA) is one of the most abundant fatty acids in the brain and its disturbed metabolism may be associated with neurological disorders such as AD and bipolar disorder [144]. Interestingly, $\mathrm{Bu}$ et al. [145] recently reported a $60 \mu \mathrm{M}$ affinity specific binding site of ferritin for ARA. Also, they described that its binding enhances iron mineralization and decreases iron release at the same time that protects the fatty acid from oxidation. This binding site was proposed to be located in the 2-fold intersubunit pocket, allowing the ARA tail to project well into the ferrihydrite mineralization site on the L-ferritin subunit, while shorter saturated fatty acids as caprylate were described not to have significant effects on mineralization.

As stated in previous sections, iron(II) can be released from ferritin by reductants small enough to reach the mineral core by using the ferritin channels, and this is the case of $\mathrm{O}_{2}{ }^{-}$. Interestingly, two distinct research groups reported diverging results with respect to the capability of $\mathrm{O}_{2}{ }^{--}$to affect the release of iron(II) from ferritin and this implied the participation of two other biomolecules: SOD and xanthine oxidase. Both, the research groups of Biemond et al. [146] and of Thomas et al. [147] found that iron was mobilized from ferritin by xanthine oxidase. However, after observation that iron release could be completely inhibited by SOD, Thomas et al. concluded that $\mathrm{O}_{2}{ }^{--}$was the active iron-mobilizing species. Similar conclusions can be drawn from the studies between the interaction of ferritin with cytochrome P-450 [148] or with the intracellularly ocurring $\mathrm{Cu}(\mathrm{I})$-glutathione complex $\mathrm{Cu}(\mathrm{GSH})_{2}$ [149]. Oppositely, the observation that SOD had no blocking effect on the release of iron from ferritin by xanthine oxidase, led to Biemond et al. to suggest that probably electrons were transferred from the enzyme-substrate 
complex to ferritin via an unknown mechanism. Finally, Bolann and Ulvik reported that in hypoxic tissues xanthine oxidase can release iron from ferritin by an $\mathrm{O}_{2}{ }^{\text {- }}$ independent process [150].

\section{Concluding remarks}

Over millions of years, living organisms have produced ferritin for a crucial function: iron storage. Ferritin is at the center of iron metabolism, providing protection by scavenging free iron and storing iron when needed. Dysfunction in ferritin, either at iron uptake or iron release leads to the existence of free iron(II), which can be the beginning of a range of neurological pathologies.

The enormous progress made in understanding the mechanism of action of ferritin, nevertheless, revealed a number of transcendent issues that still remain to be solved such as: (i) the influence of the $\mathrm{H}$ - or L-nature of its subunits in the formation of the iron core, (ii) the identification of the putative ferritin-binding biomolecules that can promote iron release or (iii) the role and interference of metals and metalloproteins in ferritin iron uptake and iron release. This review has been mainly focused in the last issue. However, much more data collecting information from realistic scenarios where other free metal ions different than iron, and other metalloproteins interact with ferritin are still needed. It is our belief that this review will provide a basis of knowledge from where to extract comprehensive conclusions and to build future prospects.

We have reviewed different situations in which the interaction of ferritin with a metal ion or a metalloprotein gives rise to the existence of free toxic metals, iron or iron plus other metals. For example, it is true that zinc(II) can be found at high concentrations in neurons but fortunately it is mainly complexed or compartimentalized. However, any anomalous zinc(II) metabolism provoking the appearance of free zinc(II) in neuron would cause an inhibition of the ferroxidase activity of ferritin and the subsequent existence of not stored free iron(II). Then, the free zinc(II) and iron(II) would result in causing neuron death. Interestingly, the presence of the multicopper ceruloplasmine could overcome this problem as this protein promotes iron(II) oxidation and also ferritin reconstitution. This is a genuine example to show how the metabolism of these three metals is interrelated 
and how its study in depth requires a full approach where interactions between free and protein-containing metals must be considered.

In another scenario, an excessive proportion of H-subunits in ferritin can result in an increase of iron(II) oxidation level but a in significant decrease of the amount of iron stored in the mineral core of ferritin, with the consequent existence of free iron(III), which is capable to oxidize some metalloproteins, such as metallothioneins, ultimately leading to the liberation of metal ions like copper(I) or zinc(II). Likewise, the iron(III) stored in the mineral core of ferritin can also oxidize the metal-MT complexes causing the liberation of iron(II) and of the metal ions bound to metallothioneins.

Although we are aware of the evident difficulties associated with the study of more integrative systems, it is our conviction that the future goals for the elucidation of the iron uptake and release processes in ferritin should aim at considering not only the presence of distinct metals but also that of other metalloproteins, which coexist with ferritin in the different tissues and cell compartments. It is our belief that only with this approach, a realistic view of the chemical implications of their interactions can be achieved. This is especially important in the brain when trying to shed light into the neuropathologies associated with the dysfunction of metalloproteins that give rise to an uncontrolled release of metals, a fact that probably underlines the origin of some of the most dramatic neurological diseases affecting nowadays the worldwide population.

\section{Acknowledgments}

This work was supported by the "Spanish Ministerio de Ciencia e Innovación," MICINN and FEDER (grants BIO2012-39682-C02-01 and BIO2012-39682-C02-02 respectively to S.A. and M.C., and CTQ2012-32236 to J.M.D.-V.). Authors from Barcelona Universities are members of the 2009SGR-1457 "Grup de Recerca de la Generalitat de Catalunya." Authors from the Universidad de Granada and Jaen are members of the FQM-368 "Grupo de Investigacion de la Junta de Andalucia." 


\section{References}

[1] R. Crichton, Inorganic Biochemistry of Iron Metabolism: from Molecular Mechanisms to Clinical Consequences, John Wiley \& Sons, England, 2001.

[2] D.J. Pinero, J.R. Connor, in: H.R. Lieberman, R.B. Kanarek, C. Prasad (Eds.), Nutritional Neuroscience, CRC Press, Taylor \& Francis Group, Boca Raton, 2005, p. 235.

[3] K. Jomova, M. Valko, Curr. Pharm. Des. 17 (2011) 3460.

[4] H. Heli, S. Mirtorabi, K. Karimian, Expert Opinion on Therapeutic Patents 21(2011) 819.

[5] N.D. Chasteen, P.M. Harrison, J. Struct. Biol. 126 (1999) 182.

[6] F.M. Michel, L. Ehm, S.M. Antao, P.L. Lee, P.J. Chupas, G. Liu, D.R. Strongin, M.A.A. Schoonen, B.L. Phillips, J.B. Parise, Science 316 (2007) 1726.

[7] N. Gálvez, B. Fernández, P. Sánchez, R. Cuesta, M. Ceolín, M. Clemente, S. Trasobares, M. López-Haro, J.J. Calvino, O. Stéphan, J.M. Domínguez-Vera, J. Am. Chem. Soc. 130 (2008) 8062.

[8] S.P. Martsev, A.P. Vlasov, P. Arosio, Protein Eng. 11 (1998) 377.

[9] S. Levi, S.J. Yewdall, P.M. Harrison, P. Santambrogio, A. Cozzi, E. Rovida, A. Albertini, P. Arosio, Biochem. J. 288 (1992) 591.

[10] P.D. Hempstead, S.J. Yewdall, A.R. Fernie, D.M. Lawson, P.J. Artymiuk, D.W. Rice, G.C. Ford, P.M. Harrison, J. Mol. Biol. 268 (1997) 424. [11] E.C. Theil, Curr. Opin. Struct. Biol. 15 (2011) 304.

[12] M. Wagstaff, M. Worwood, A. Jacobs, Biochem. J. 173 (1978) 969.

[13] J. Zähringer, B.S. Baliga, H.N. Munro, Proc. Natl. Acad. Sci. U.S.A. 73 (1976) 857.

[14] K. Iwai, S.K. Drake, N.B. Wehr, A.M. Weissman, T. LaVaute, N. Minato, R.D. Klausner, R.L. Levine, T.A. Rouault, Proc. Natl. Acad. Sci. U.S.A. 95 (1998) 4924.

[15] S.V. Torti, E.L. Kwak, S.C. Miller, L.L. Miller, G.M. Ringold, K.B. Myambo, A.P. Young, F.M. Torti, J. Biol. Chem. 263 (1988) 12638.

[16] D. Berg, G. Beceker, P. Riederer, O. Rieb, Neurotox. Res. 4 (2002) 637. 
[17] B. Uttara, A.V. Singh, P. Zamboni, R.T. Mahajan, Curr. Neuropharmacol. 7 (2009) 65.

[18] H. Kozlowski, M. Luczkowski, M. Remelli, D. Valensin, Coord. Chem. Rev. 256 (2012) 2129.

[19] A. Binolfi, L. Quintanar, C.W. Bertoncini, C. Griesinger, C.O. Fernández, Coord. Chem. Rev. 256 (2012) 2188.

[20] C. Hureau, P. Dorlet, Chem. Rev. 256 (2012) 2175. [21] J.H. Viles, Coord. Chem. Rev. 256 (2012) 2271.

[22] J.M. Domínguez-Vera, B. Fernández, N. Galvez, Future Med. Chem. 2 (2010) 609.

[23] A.R.J. Curtis, C. Fey, C.M. Morris, L.A. Bindoff, P.G. Ince, P.F. Chinnery, A.

Coulthard, M.J. Jackson, A.P. Jackson, D.P. McHale, D. Hay, W.A. Barker, A.F. Markham, D. Bates, A. Curtis, J. Burn, Nat. Genet. 28 (2001) 350.

[24] J. Kato, K. Fujikawa, M. Kanda, N. Fukuda, K. Sasaki, T. Takayama, M. Kobune, K. Takada, R. Takimoto, H. Hamada, T. Ikeda, Y. Niitsu, Am. J. Hum. Genet. 69 (2001) 191.

[25] M.E. Martin, S. Fargion, P. Brissot, B. Pellat, C. Beaumont, Blood 91 (1998) 319. [26] R.K. Watt, R.J. Hilton, D.M. Graff, Biochim. Biophys. Acta 1800 (2010) 745. [27] J.G. Joshi, A. Zimmerman, Toxicology 48 (1988) 21.

[28] S. Pead, E. Durrant, B. Webb, C. Larsen, D. Heaton, J. Johnson, G.D. Watt, J. Inorg. Biochem. 59 (1995) 15.

[29] I.G. Macara, T.G. Hoy, P.M. Harrison, Biochem. J. 135 (1973) 785.

[30] A. Mazur, S. Green, A. Saha, A. Carleton, J. Clin. Invest. 37 (1985) 18097. [31] S.-H. Juan, J.-H. Guo, S.D. Aust, Arch. Biochem. Biophys. 341 (1997) 280.

[32] G.R. Bakker, R.F. Boyer, J. Biol. Chem. 261 (1986) 13182.

[33] N.E. Le Brun, A.M. Keech, M.R. Mauk, A.G. Mauk, S.C. Andrews, A.J. Thomson, G.R. Moore, FEBS Lett. 397 (1996) 159.

[34] A. Treffry, P.M. Harrison, J. Inorg. Biochem. 21 (1984) 9. 
[35] X. Yang, N.E. Le Brun, A.J. Thomson, G.R. Moore, N.D. Chasteen, Biochemistry $39(2000) 4915$.

[36] T.J. Stillman, P.D. Hempstead, P.J. Artymiuk, S.C. Andrews, A.J. Hudson, A. Treffry, J.R. Guest, P.M. Harrison, J. Mol. Biol. 307 (2001) 587.

[37] F. Bou-Abdallah, P. Arosio, S. Levi, C. Janus-Chandler, N.D. Chasteen, J. Biol. Inorg. Chem. 8 (2003) 489.

[38] L. Toussaint, L. Bertrand, L. Hue, R.R. Crichton, J.P. Declercq, J. Mol. Biol. 365 (2007) 440.

[39] M.J. Yablonski, E.C. Theil, Biochemistry 31 (1992) 9680.

[40] J. McKnight, N. White, G.R. Moore, J. Chem. Soc. Dalton Trans. (1997) 4043. [41] C.A. Reilly, M. Sorlie, S.D. Aust, Arch. Biochem. Biophys. 354 (1998) 165, and references therein.

[42] R. Orihuela, B. Fernández, O. Palacios, E. Valero, S. Atrian, R.K. Watt, J.M.

Domínguez-Vera, M. Capdevila, Chem. Commun. 47 (2011) 12155. [43] P.M. Proulx-Curry, N.D. Chasteen, Coord. Chem. Rev. 144 (1995) 347. [44] R.C. Hider, X. Kong, Dalton Trans. 42 (2013) 3220.

[45] P.M. Harrison, P. Arosio, Biochim. Biophys. Acta 1275 (1996) 161.

[46] E.C. Theil, R.K. Behera, T. Tosha, Coord. Chem. Rev. 257 (2013) 579, and references therein.

[47] T. Douglas, D.R. Ripoll, Protein Sci. 7 (1998) 1083. [48] X. Liu, E.C. Theil, Acc. Chem. Res. 38 (2005) 167.

[49] T. Tosha, H-L. Ng, O. Bhattasali, T. Alber, E.C. Theil, J. Am. Chem. Soc. 132 (2010) 14562.

[50] F. Bou-Abdallah, G.C. Papaefthymiou, D.M. Scheswohl, S.D. Stanga, P. Arosio, N.D. Chasteen, Biochem. J. 364 (2002) 57.

[51] X. Liu, E.C. Theil, Proc. Natl. Acad. Sci. U.S.A. 101 (2004) 8557.

[52] J. Tatur, W.R. Hagen, P.M. Matias, J. Biol. Inorg. Chem. 12 (2007) 615. 
[53] J. Hwang, C. Krebs, B.H. Huynh, D.E. Edmondson, E.C. Theil, J.E. Penner-Hahn, Science 287 (2000) 122.

[54] A. Crow, T.L. Lawson, A. Lewin, G.R. Moore, N.E. Le Brun, J. Am. Chem. Soc. 131 (2009) 6808.

[55] I. Bertini, D. Lalli, S. Mangani, C. Pozzi, C. Rosa, E.C. Theil, P. Turano, J. Am.

Chem. Soc. 134 (2012) 6169.

[56] P. Turano, D. Lalli, I.C. Felli, E.C. Theil, I. Bertini, Proc. Natl. Acad. Sci. U.S.A. 107 (2010) 545.

[57] K.H. Ebrahimi, P.-L. Hagedoorn, W.R. Hagen, J. Biol. Inorg. Chem. 15 (2010) 1243.

[58] J. Tatur, W.R. Hagen, FEBS Lett. 579 (2005) 4729.

[59] K.H. Ebrahimi, P.L. Hagedoorn, J.A. Jangejon, W.R. Hagen, J. Biol. Inorg. Chem. 14 (2009) 1265.

[60] N.E. Le Brun, A. Crow, M.E.P. Murphy, A.G. Mauk, G.R. Moore, Biochim. Biophys. Acta 1800 (2010) 732.

[61] A. Lewin, G.R. Moore, N.E. Le Brun, Dalton Trans. (2005) 3597.

[62] J.L. Johnson, M. Cannon, R.K. Watt, R.B. Frankel, G.D. Watt, Biochemistry 38 (1999) 6706.

[63] J.S. Rohrer, Q.T. Islam, G.D. Watt, D.E. Sayes, E.C. Theil, Biochemistry 29 (1990) 259.

[64] A. Treffry, P.M. Harrison, Biochem. J. 171 (1978) 313. [65] R.J. Hilton, A. David, R.K. Watt, Biometals 25 (2012) 259.

[66] J.D. López-Castro, J.J. Delgado, J.A. Perez-Omil, N. Galvez, R. Cuesta, R.K. Watt, J.M. Domínguez-Vera, Dalton Trans. 41 (2012) 1320.

[67] F. Carmona, O. Palacios, S. Atrian, J.M. Dominguez-Vera, M. Capdevila, under review.

[68] Q.Q. Pankhursta, D. Hautotb, N. Khanc, J. Dobson, J. Alzheimers Dis. 13 (2008) 49. 
[69] S. Yasmin, S.C. Andrews, G.R. Moore, N.E. Le Brun, J. Biol. Chem. 286 (2011) 3473.

[70] S. Sirivech, E. Frieden, S. Osaki, Biochem. J. 143 (1974) 311.

[71] M.S. Joo, G. Tourillon, D.E. Sayers, E.C. Theil, Biol. Met. 3 (1990) 171. [72] D.C. Harris, Biochemistry 17 (1978) 3071.

[73] J. Johnson, J. Kenealey, R.J. Hilton, D. Brosnahan, R.K. Watt, G.D. Watt, J. Inorg. Biochem. 105 (2011) 202.

[74] X. Liu, W. Jin, E.C. Theil, Proc. Natl. Acad. Sci. U.S.A. 100 (2003) 3653.

[75] N. Gálvez, B. Ruiz, R. Cuesta, E. Colacio, J.M. Domínguez-Vera, Inorg. Chem. 44 (2005) 2706.

[76] F. Bou-Abdallah, J. McNally, X.X. Liub, A. Melman, Chem. Commun. 47 (2011) 731.

[77] P. Sánchez, N. Gálvez, E. Colacio, E. Miñ ones, J.M. Domínguez-Vera, Dalton Trans. (2005) 811.

[78] W. Linert, G.N.L. Jameson, J. Inorg. Biochem. 79 (2000) 319.

[79] G.N.L. Jameson, W. Linert, in: G. Poli, E. Cadenas, L. Packer (Eds.), Free Radicals in Brain Pathophysiology, Marcel-Decker, New York, 2000, p. 247.

[80] G.D. Watt, D. Jacobs, R.B. Frankel, Proc. Natl. Acad. Sci. U.S.A. 85 (1988) 7457.

[81] S.K. Weeratunga, C.E. Gee, S. Lovell, Y. Zeng, C.L. Woodin, M. Rivera, Biochemistry 48 (2009) 7420.

[82] V. Subramanian, D.G. Evans, J. Phys. Chem. B 116 (2012) 9287.

[83] H. Shi, K.Z. Bencze, T.L. Stemmler, C.C. Philpott, Science 320 (2008) 1207. [84] D.H. Boldt, Am. J. Med. Sci. 318 (1999) 207.

[85] J. Connor, in: J. Connor (Ed.), Metals and Oxidative Damage in Neurological Disorders, Plenum Press, New York, 1997, p. 23.

[86] J.R. Connor, S.A. Benkovic, Ann. Neurol. 32 (1992) S51.

[87] J. Galazka-Friedman, A. Friedman, Acta Neurobiol. Exp. 57 (1997) 217. 
[88] M.B.H. Youdim, D. Ben-Shachar, P. Riederer, Acta Neurol. Scand. 126 (1989) 47.

[89] R.A. Cherny, C.S. Atwood, M.E. Xilinas, D.N. Gray, W.D. Jones, C.A. McLean, K.J. Barnham, I. Volitakis, F.W. Fraser, Y. Kim, X. Huang, L.E. Goldstein, R.D. Moir, J.T. Lim, K. Beyreuther, H. Zheng, R.E. Tanzi, C.L. Masters, A.I. Bush, Neuron 30 (2001) 665.

[90] M. Perez, J.M. Valpuesta, E.M. De Garcini, C. Quintana, M. Arrasate, J.L. LopezCarrascosa, A. Rabano, J.G. De Yebenes, J. Avila, Am. J. Pathol. 152 (1998) 1531.

[91] A. Takeda, M. Hashimoto, M. Mallory, M. Sundsumo, L. Hansen, A. Sisk, E. Masliah, Lab. Invest. 78 (1998) 1169.

[92] M. Hashimoto, E. Masliah, Brain Pathol. 9 (1999) 707.

[93] D.T. Dexter, C.J. Carter, F.R. Wells, F. Javoy-Agid, Y. Agid, A. Lees, P. Jenner, C.D. Marsden, Brain 114 (1991) 1953.

[94] B. Hallgren, P. Sourander, J. Neurochem. 3 (1958) 41.

[95] J. Sian-Huelsmann, S. Mandel, M.B.H. Youdim, P. Riederer, J. Neurochem. 118 (2011) 939.

[96] J.R. Connor, K.L. Boeshore, S.A. Benkovic, S.L. Menzies, J. Neurosci. Res. 37 (1994) 461.

[97] J.R. Connor, B.S. Snyder, P. Arosio, D.A. Loefer, P. Le Witt, J. Neurochem. 65 (1995) 717.

[98] P. Ponka, C. Beaumont, D. Richardson, Semin. Hematol. 35 (1998) 35.

[99] L. Zecca, M.B. Youdim, P. Riederer, J.R. Connor, R.R. Crichton, Nat. Rev. Neurosci. 5 (2004) 863.

[100] J. Galazka-Friedman, Hyperfine Interact. 182 (2008) 31. [101] C.J. Frederickson, Int. Rev. Neurobiol. 31 (1989) 145. [102] A. Takeda, Brain Res. 34 (2000) 137.

[103] R.A. Colvin, Am. J. Physiol. Cell Physiol. 282 (2002) 317. [104] C.E. Outten, T.V. O’Halloran, Science 292 (2001) 2488. [105] L.A. Finney, T.V. O’Halloran, Science 300 (2003) 931. 
[106] I. Bertini, L. Decaria, A. Rosato, J. Biol. Inorg. Chem. 15 (2010) 1071. [107] L. Decaria, I. Bertini, R.J.P. Williams, Metallomics 2 (2010) 706. [108] W. Maret, Y. Li, Chem. Rev. 109 (2009) 4682.

[109] A. Takeda, Biometals 14 (2001) 343.

[110] C.J. Frederickson, J.Y. Koh, A.I. Bush, Nat. Rev. Neurosci. 6 (2005) 449. [111] D.W. Choi, M. Yokoyama, J.K. Koh, Neuroscience 24 (1988) 67.

[112] G.J. Lees, A. Lehmann, M. Sandberg, A. Hamberger, Neurosci. Lett. 120 (1990) 155.

[113] M. Capdevila, R. Bofill, O. Palacios, S. Atrian, Coord. Chem. Rev. 256 (2012) 46.

[114] J. Hidalgo, R. Chung, M. Penkowa, M. Vasak, in: A. Sigel, H. Sigel, R.K.O. Sigel (Eds.), Metallothioneins and Related Chelators, Metal Ions in Life Sciences, vol. 5, RSC Publishing, Cambridge, 2009, p. 279.

[115] Y. Uchida, Biol. Signals 3 (1994) 211.

[116] M. Vasak, G. Meloni, in: A. Sigel, H. Sigel, R.K.O. Sigel (Eds.), Metallothioneins and Related Chelators, Metal Ions in Life Sciences, vol. 5, RSC Publishing, Cambridge, 2009, p. 319.

[117] S. Atrian, M. Capdevila, Biomolecular Concepts (2013),

http://dx.doi.org/10.1515/bmc-2012-0049.

[118] W. Maret, A. Krezel, Mol. Med. 13 (2007) 371. [119] C.-J. Chen, S.-L. Liao, J. Neurochem. 85 (2003) 443.

[120] E. Gaggelli, H. Kozlowski, D. Valensin, G. Valensin, Chem. Rev. 106 (2006) 1995.

[121] T.D. Rae, P.J. Schmidt, R.A. Pufahl, V.C. Culotta, T.V. O’Halloran, Science 284 (1999) 805.

[122] K.M. Davies, D.J. Hare, V. Cottam, N. Chen, L. Hilgers, G. Halliday, J.F.B. Mercer, K.L. Double, Metallomics 5 (2013) 43.

[123] L. Decaria, I. Bertini, R.J.P. Williams, Metallomics 3 (2011) 56. 
[124] T.C. Steveson, G.D. Ciccotosto, X.M. Ma, G.P. Mueller, R.E. Mains, B.A. Eipper, Endocrynology 144 (2003) 188.

[125] L.W.J. Klomp, Z.S. Farhangrazi, L.L. Dugan, J.D. Gitlin, J. Clin. Invest. 98 (1996) 207.

[126] G. Meloni, V. Sonois, T. Delaine, L. Guilloreau, A. Gillet, J. Teissie, P. Faller, M. Vasak, Nat. Chem. Biol. 4 (2008) 366.

[127] G. Meloni, M. Vasak, Free Radic. Biol. Med. 50 (2011) 1471.

[128] K. Yoshida, K. Furihata, S. Takeda, A. Nakamura, K. Yamamoto, H. Morita, S. Hiyamuta, S. Ikeda, N. Shimizu, N. Yanagisawa, Nat. Genet. 9 (1995) 267.

[129] Z.L. Harris, Y. Takahashi, H. Miyajima, M. Serizawa, R.T.A. MacGillivray, J.D. Gitlin, Proc. Natl. Acad. Sci. U.S.A. 92 (1995) 2539.

[130] N.D. Chasteen, S. Sun, S. Levi, P. Arosio, in: C. Hershko (Ed.), Progress in Iron Research, Plenum, New York, 1994, p. 23.

[131] P.J. Artymiuk, E.R. Bauminger, P.M. Harrison, D.M. Lawson, I. Nowik, A. Treffry, S.J. Yewdall, in: R.B. Frankel, R.P. Blakemore (Eds.), Iron Biominerals, Plenum Press, New York, 1991, p. 269.

[132] D.E. Bacelo, R.C. Binning Jr., Chem. Phys. Lett. 507 (2011) 174.

[133] J.A. Duce, A. Tsatsanis, M.A. Cater, S.A. James, E. Robb, K. Wikhe, S.L. Leong, K. Perez, T. Johanssen, M.A. Greenough, H.-H. Cho, D. Galatis, R.D. Moir, C.L. Masters, C. McLean, R.E. Tanzi, R. Cappai, K.J. Barnham, G.D. Ciccotosto, J.T. Rogers, A.I. Bush, Cell 142 (2010) 857.

[134] K.H. Ebrahimi, P.-L. Hagedoorn, W.R. Hagen, PLoS One 7 (2012) e40287. [135] N.E. Hellman, J.D. Gitlin, Annu. Rev. Nutr. 22 (2002) 439.

[136] M.E. Van Eden, S.D. Aust, Arch. Biochem. Biophys. 381 (2000) 119, and enclosed references.

[137] O. Palacios, S. Atrian, M. Capdevila, J. Biol. Inorg. Chem. 16 (2011) 991. 
[138] H. Yao, Y. Wang, S. Lovell, R. Kumar, A.M. Ruvinsky, K.P. Battaile, I.A. Vakser, M. Rivera, J. Am. Chem. Soc. 134 (2012) 13470.

[139] M. Hashimoto, Y. Nambo, T. Kondo, K. Watanabe, K. Orino, J. Equine Sci. 22 (2011) 1, and references therein.

[140] A. Usami, M. Tanaka, Y. Yoshikawa, K. Watanabe, H. Ohtsuka, K. Orino, Biometals 24 (2011) 1217, and references therein.

[141] F. Langhauser, E. Göb, P. Kraft, C. Geis, J. Schmitt, M. Brede, K. Göbel, X. Helluy, M. Pham, M. Bendszus, P. Jakob, G. Stoll, S.G. Meuth, B. Nieswandt, K.R. McCrae, C. Kleinschnitz, Blood 120 (2012) 4082.

[142] D.M. Kovacs, Exp. Gerontol. 35 (2000) 473.

[143] C. Schachtrup, J.K. Ryu, M.J. Helmrick, E. Vagena, D.K. Galanakis, J.L. Degen, R.U. Margolis, K. Akassoglou, J. Neurosci. 30 (2010) 5843.

[144] S.I. Rapoport, J. Nutr. 138 (2008) 2515.

[145] W. Bu, R. Liu, J.C. Cheung-Lau, I.J. Dmochowski, P.J. Loll, R.G. Eckenhoff, FASEB J. 26 (2012) 2394.

[146] P. Biemond, H.G. van Eijk, A.J.G. Swaak, J.F. Koster, J. Clin. Invest. 73 (1984) 1576.

[147] C.E. Thomas, L.A. Morehouse, S.D. Aust, J. Biol. Chem. 260 (1985) 3275. [148] S. Puntarulo, A.I. Cederbaum, Biochim. Biophys. Acta 1289 (1996) 238.

[149] M.E. Aliaga, C. Carrasco-Pozo, C. López-Alarcón, C. Olea-Azar, H. Speisky, Bioorg. Med. Chem. 19 (2011) 534.

[150] B.J. Bolann, R.J. Ulvik, Biochem. J. 243 (1987) 55. 